\title{
How Harmful Is Particulate Matter Emitted from Biomass Burning? A Thailand Perspective
}

\author{
Helinor J. Johnston ${ }^{1} \cdot$ William Mueller ${ }^{2} \cdot$ Susanne Steinle ${ }^{2} \cdot$ Sotiris Vardoulakis $^{2} \cdot$ Kraichat Tantrakarnapa $^{3}$. \\ Miranda Loh ${ }^{2} \cdot$ John W. Cherrie ${ }^{1,2}$
}

Published online: 11 November 2019

(C) The Author(s) 2019

\begin{abstract}
Purpose of Review A large body of epidemiological evidence demonstrates that exposure to particulate matter (PM) is associated with increased morbidity and mortality. Many epidemiology studies have investigated the health effects of PM in Europe and North America and focussed on traffic derived PM. However, elevated levels of PM are a global problem and the impacts of other sources of PM on health should be assessed. Biomass burning can increase PM levels in urban and rural indoor and outdoor environments in developed and developing countries. We aim to identify whether the health effects of traffic and biomass burning derived PM are similar by performing a narrative literature review. We focus on Thailand as haze episodes from agricultural biomass burning can substantially increase PM levels.

Recent Findings Existing epidemiology, in vitro and in vivo studies suggest that biomass burning derived PM elicits toxicity via stimulation of oxidative stress, inflammation and genotoxicity. Thus, it is likely to cause similar adverse health outcomes to traffic PM, which causes toxicity via similar mechanisms. However, there is conflicting evidence regarding whether traffic or biomass burning derived PM is most hazardous. Also, there is evidence that PM released from different biomass sources varies in its toxic potency.

Summary We recommend that epidemiology studies are performed in Thailand to better understand the impacts of PM emitted from specific biomass sources (e.g. agricultural burning). Further, experimental studies should assess the toxicity of PM emitted from more diverse biomass sources. This will fill knowledge gaps and inform evidence-based interventions that protect human health.
\end{abstract}

Keywords Particulate Matter PM10 P PM2.5 - Biomass burning · Toxicity · Air pollution · Hazard · In vitro · In vivo · Epidemiology $\cdot$ Thailand

This article is part of the Topical Collection on Human Health Effects of Environmental Pollution

Helinor J. Johnston

h.johnston@hw.ac.uk

1 School of Engineering and Physical Sciences, Institute of Biological Chemistry, Biophysics and Bioengineering, Heriot-Watt University, Edinburgh EH14 4AS, UK

2 Institute of Occupational Medicine, Research Avenue North, Riccarton, Edinburgh EH14 4AP, UK

3 Department of Social and Environmental Medicine, Faculty of Tropical Medicine, Mahidol University, 420/6 Ratchawithi Road, Ratchathewi, Bangkok 10400, Thailand

\section{Introduction}

A large body of epidemiological evidence has clearly demonstrated that short- and long-term exposure to particulate matter (PM) is associated with increased morbidity and mortality (e.g. [1-7], reviewed in [8-15]). A broad range of health effects are associated with PM exposure, which are summarised in Fig. 1. There is compelling evidence that PM has detrimental impacts on the respiratory and cardiovascular systems. For example, poor air quality is associated with an increased incidence of stroke and myocardial infarctions, an increase in emergency hospital admissions related to asthma, chronic obstructive pulmonary disease (COPD), respiratory infections and an increased incidence of lung cancer (Fig. 1). There is also emerging evidence that exposure to PM increases risk for neurological (e.g. dementia, cognitive impairment) and metabolic (e.g. diabetes) diseases and that PM can cause 

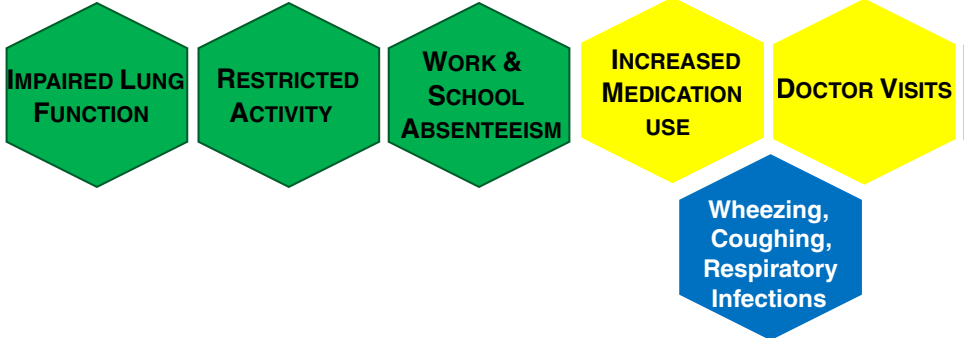
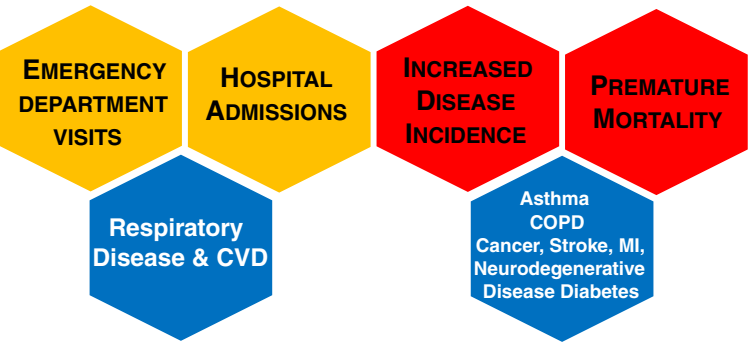

\section{SeVERIty Of HeALth EFFECT}

Fig. 1 Examples of the adverse health impacts associated with exposure to particulate air pollution. Short- and long-term exposure to PM can cause a spectrum of adverse health outcomes, which vary in their

reproductive and developmental toxicity [12, 16-22] (Fig. 1). Susceptibility to the health impacts of PM can vary with respect to health, age and socioeconomic status [10]. For example, it is established that individuals with pre-existing disease (e.g. asthma, COPD, cardiovascular disease), young children and the elderly are more vulnerable to the toxicity of PM [10]. Socioeconomic status is also important, with adverse health impacts occurring more frequently in economically disadvantaged groups [10]. Due to concerns regarding PM toxicity, air quality standards have been adopted globally to protect the general public [10].

The bulk of evidence available on the health impacts of PM is mainly associated with exposure to urban (e.g. traffic derived) PM, with relatively fewer studies addressing the toxicity of PM specifically emitted from other emission sources, such as biomass burning. In Southeast (SE) Asia, haze episodes from agricultural biomass burning commonly occur each year [23]. More specifically, fire is used to clear agricultural land in SE Asia, and the resulting smoke (termed haze) can spread to other regions and countries causing transboundary pollution. During haze events, pollutant levels can remain elevated for long periods, thereby having a detrimental impact on air quality [24]. Biomass burning therefore has the potential to substantially contribute to and elevate ambient PM levels, so there is a need to understand whether the implications for health following exposure to biomassderived PM are the same as those observed for PM emitted from other sources (e.g. traffic). In this review, as part of the Thailand Air Pollution and Health Impact Assessment (TAPHIA) study, we have performed a narrative review of the available literature to identify whether PM emitted from biomass burning is toxic in order to (1) identify whether the health effects of urban (e.g. traffic) and biomass burning derived PM are similar by examining the findings from epidemiology, in vivo and in vitro studies, and (2) recommend future research priorities that will address current knowledge gaps relating to the toxicity of biomass burning-derived PM in order to strengthen the evidence base, and inform interventions to protect human health. We will focus our severity. Adapted from [15]. COPD = chronic obstructive pulmonary disease, $\mathrm{CVD}=$ cardiovascular disease, $\mathrm{MI}=$ myocardial infarction

recommendations on Southeast Asia, and in particular on Thailand where biomass burning is an important source of PM emissions and overall exposures, and where currently the impacts of PM emitted from burning biomass on human health are uncertain.

\section{Contribution of Emission Source to PM Toxicity: a Global Perspective}

To demonstrate adherence to regulatory limits and to protect human health, ambient air pollutant levels are monitored in many large urban and rural locations across the world, with World Health Organisation (WHO) guideline levels set at a $24 \mathrm{~h}$ mean of $25 \mu \mathrm{g} / \mathrm{m}^{3} / 50 \mu \mathrm{g} / \mathrm{m}^{3} \mathrm{PM}_{2.5} / \mathrm{PM}_{10}$ (i.e. PM with an aerodynamic diameter smaller than 2.5 and $10 \mu \mathrm{m}$, respectively) and an annual mean of $10 \mu \mathrm{g} / \mathrm{m}^{3} / 20 \mu \mathrm{g} / \mathrm{m}^{3}$ for $\mathrm{PM}_{2.5} /$ $\mathrm{PM}_{10}$ [10]. These guidelines assume that all PM is equally toxic. However, PM emitted from different sources vary with respect to their physico-chemical properties (e.g. composition, shape, size and surface area), which potentially influences PM toxicity.

The impacts of PM on human health are relevant globally, in both urban and rural settings. The majority of epidemiology studies conducted to date have been performed in Europe and North America, but poor air quality associated with elevated levels of PM is a global problem. Importantly, the sources of pollution varies in different countries, influencing the level of PM exposure, and the physico-chemical properties of the emitted PM [25]. Regardless of source, PM is likely to elicit detrimental health effects; however, the specific role of PM sources in inducing adverse health impacts is still very much under investigation [26]. Untangling whether the source of PM influences its toxicity is essential as, whilst there is agreement that elevated levels of PM are associated with adverse health effects, harmful effects can be observed when PM levels are within permitted levels (e.g. [27, 28]). Though it is not possible to have an absence of PM (as PM also comes from natural, as well as anthropogenic sources), it is important 
to understand whether PM from specific anthropogenic sources varies in its toxicity, since this can help prioritise source control measures and ultimately protect public health [29-32].

It has been hypothesised that the ultrafine particle component of PM (i.e. PM with an aerodynamic diameter smaller than $100 \mathrm{~nm}$ ) is primarily responsible for its toxicity [33]. Experimental (laboratory) studies extensively investigated the cell and molecular mechanism of toxicity of air pollution particles to understand why adverse health effects were observed in epidemiology studies. The studies found that the ultrafine particles in PM stimulated oxidative stress and inflammation in the lung following inhalation, which led to detrimental health outcomes (for reviews, see [34-37]). Existing laboratory studies that investigated the toxicity of PM primarily assessed the toxicity of $\mathrm{PM}_{10}$ samples obtained from traffic sources, or used ultrafine carbon black (ufCB; i.e. carbon particle with a diameter of $14 \mathrm{~nm}$ ) as a surrogate for traffic-derived $\mathrm{PM}_{10}$. However, $\mathrm{PM}$ is heterogeneous, and variations in the characteristics of particles (e.g. particle size and surface area, and composition [e.g. polyaromatic hydrocarbon (PAH), metal, and endotoxin content]) released from different emission sources can influence the biological response (reviewed by [10, 12, 38]). Variance in the hazard of PM emitted from different sources (e.g. biomass burning) is therefore expected as they are likely to have different physicochemical properties to that emitted from traffic.

\section{Contribution of Biomass Burning to Ambient PM Levels}

Burning of fossil fuels is the main source of ambient PM in the developing world (reviewed in [11, 13]). In urban areas, road traffic is typically the primary source of PM [39]. However, biomass burning can also increase the burden of PM in environments that span urban and rural locations, indoor and outdoor settings, as well as developed and developing countries $[40,41]$. Activities that generate PM emissions from biomass combustion include electricity generation, commercial and domestic emissions (e.g. cooking, heating), agriculture, waste and natural emissions [40, 42]. Examples of open biomass burning include burning of agricultural waste, forest fires, wild fires, bushfires and land clearing, whereas examples of enclosed biomass burning includes domestic biofuel burning (e.g. wood, animal dung, crop residues) for cooking and heating and domestic/industrial burning for electricity [43]. As the use of renewable energy is appealing for many reasons (e.g. rising cost of using fossil fuels) in developed and developing countries, this has led to an increase in burning of biomass fuels globally [11].

To date, biomass burning-derived PM has primarily been a health concern for developing countries. However, exposure to biomass PM is increasing in developed countries mainly when used for domestic heating purposes, but also increasingly from wild fires, and can substantially contribute to ambient PM concentrations, particularly in winter months (reviewed in $[41,44])$. For example, Glasius et al. assessed the influence of residential wood burning on local air quality in a rural town in Denmark (with limited traffic) and found that the levels of PM were similar to those recorded in urban areas (a busy street in Copenhagen) [45]. Furthermore, Fuller et al. demonstrated that wood burning (for domestic heating purposes) contributed to $\mathrm{PM}_{10}$ levels in London [46]. In addition, Snider et al. measured indoor and outdoor levels of PM in rural China to identify the level of PM associated with wood burning or gas/ electric stoves and found that the use of wood burning stoves was associated with up to $55 \%$ higher $\mathrm{PM}_{2.5}$ levels indoors than the use of gas/electric stoves [47]. For some European countries (e.g. Sweden, Finland, Germany and Austria), it has been estimated that $15-25 \%$ of $\mathrm{PM}_{2.5}$ particles originate from residential biomass combustion, and it is expected that by 2020, biomass burning will contribute to almost $40 \%$ of fine PM emissions in Europe (reviewed by [41]).

Over recent years, there has also been a greater frequency, size and intensity of wildfires worldwide (e.g. bush, forest, vegetation, peat and grass fires). [48, 49]. Wildfires can be a significant source of air pollution, with emissions including PM, carbon monoxide (CO), PAHs and volatile organic compounds (VOCs) [50]. Air quality is severely affected during wildfire episodes, with the levels of PM emitted resulting in concentrations greatly exceeding target (regulated) levels. For example, He et al. investigated the impact of open biomass burning (forest and farmland burning) on air quality in Brisbane, Australia, and observed that PM levels were 10 times higher than the annual average, and exceeded WHO $24 \mathrm{~h}$ guidelines during the wildfire events [43]. Artaxo and Yamasoe quantified the levels of $\mathrm{PM}_{10}$ that were emitted during biomass burning season in the Amazon Basin and found that concentrations reached 150 $700 \mu \mathrm{g} / \mathrm{m}^{3}$ (depending on the location), which is well over background $\mathrm{PM}_{10}$ concentrations of $10 \mu \mathrm{g} / \mathrm{m}^{3}$ [51]. In 2008, PM values in Sacramento River Valley (California, USA) during wildfires reached $262 \mu \mathrm{g} / \mathrm{m}^{3}$ (reviewed by [52]). Furthermore, wildfires in Southern California in 2003 saw $\mathrm{PM}_{10}$ levels increase by three- to fourfold, with one region reaching $215 \mu \mathrm{g} / \mathrm{m}^{3}$ [53]. Of additional concern is that, like other sources, PM emitted from wildfires may travel over long distances to affect regions far from the original source. Indeed, Sapkota et al. investigated the long range transport of pollutant emissions from forest fires in Quebec (Canada), and in particular, PM, and demonstrated that air quality was affected in Baltimore (USA), over a thousand kilometres from the source [50]. 


\section{Sources of PM in Thailand}

The population of Thailand is exposed to PM that is emitted from a range of different sources, with different sources dominating PM emissions in different regions of the country. For example, in the Bangkok Metropolitan Area, with a population of 12.6 million (in 2015), the number of cars on the road was 10 million and vehicle emissions were the main source of PM [54]. Emissions from power plants and industry are also large contributors of PM emissions in Thailand, particularly in areas surrounding Bangkok, including the central and eastern regions $[55,56]$. As discussed previously, there is a wealth of information available on the health impacts of urban (e.g. traffic and industry) derived PM, and thus, it is possible to infer what the potential risks posed by these sources of PM to the Thailand population are from existing epidemiology and toxicology studies.

PM emissions from biomass burning can also influence ambient PM concentrations in Thailand. In particular, the burning of forests and crop residues for agricultural purposes can impact on air quality. More specifically, anthropogenic forest fires are used to clear the land so that it can be used for agricultural purposes, as the burnt land is often considered to be nutrient rich. Agricultural land is also intentionally burnt before and after harvesting (e.g. to clear crop residues and weeds) and to prepare the land for the next crop [57]. The frequency of agriculture-related biomass burning in Thailand (as well as other SE Asian countries) varies depending on the region and crop, but the greatest activity is typically observed during the dry season (January to April) and in northern regions of the country. Agricultural burning is often performed for financial reasons due to the high cost of the machinery required for land/forest clearing, as it is often quicker and easier to perform burning than using other approaches to clear land/forests, and as in some areas, there is no easy access for the required machinery.

Phairuang et al. assessed the influence of agricultural burning (e.g. crop residues, forest fires) on air quality in the upper northern, lower northern and northeast regions in Thailand and found that these activities correlated with elevations in ambient PM concentrations [58]. Indeed, it is established that agricultural (crop) burning in Thailand leads to concentrations of PM that are well over WHO guideline levels, which is likely to increase the incidence of adverse health effects $[23,59]$. Furthermore, agricultural burning increased PM levels above national guideline levels in northern parts of the country, with the greatest effect observed during the dry season (January-April), where a tripling of the daily PM concentration was recorded [60]. In addition, markers of biomass burning in ambient PM samples, such as levoglucosan - an anhydrohexose that is produced from the pyrolysis of carbohydrates - have been shown to be up to $20 \times$ higher during the burning season in Thailand $[61,62]$.
These studies therefore indicate that PM emission sources can vary by season.

It has also been demonstrated that air quality in Thailand can be affected both in locations where biomass burning is intensive, but also in more distant regions. For example, it has been observed that the clearing of tropical forest in SE Asia for commercial agriculture causes the release of significant quantities of gases and aerosols, which disrupts air quality and produces haze in neighbouring countries [63, 64]. These transboundary effects are heavily dependent on meteorological conditions, including prevailing wind and precipitation levels. For example, Kliengchuay et al. demonstrated that air quality in the Mae Hong Son Province (in the north of Thailand) was influenced by several sources depending on the season, including local biomass burning (e.g. natural or anthropogenic forest fires and agricultural burning) and transboundary pollution, and that PM levels were strongly influenced by meteorological factors (e.g. wind direction, wind speed, rainfall, temperature) [65].

Whilst the impacts of agricultural burning on air quality in Thailand have been evaluated in several studies, it is also essential to assess the potential risks posed by the emitted $\mathrm{PM}$ on human health.

\section{Review of Epidemiology and Experimental Toxicology Studies that Have Assessed the Harmful Effects of Biomass-Derived PM}

Adverse health effects from biomass-derived PM can be assessed using epidemiology and experimental (laboratory) studies. Epidemiological studies are essential in demonstrating a link between PM exposure and detrimental impacts on human health but can be costly and time consuming to perform. Furthermore, it is more difficult to assess the toxicological mechanism of action of PM in epidemiology studies, as these are generally not controlled exposures. Therefore, in vitro and in vivo studies are often commonly used to assess the toxicity of PM. In vivo studies allow the toxicity of PM to be assessed in a whole organism, but there is a drive to move away from animal studies for ethical, financial and time reasons and also due to the fact that there are issues with the reproducibility of in vivo studies and that they may not be able to predict human responses (reviewed in [66]). In vitro studies can be criticised for their lack of physiological relevance, but these tests allow the toxicity of PM to be screened relatively cheaply and quickly. Investigation of the mechanism of toxicity of PM can also be probed using in vitro studies, which is critical in informing potential impacts on health and identifying markers to screen PM toxicity in the future. Furthermore, the use of alternatives to animal testing also has ethical benefits, and using human cells can help overcome 
issues with species differences which are apparent when using rodents [66].

Epidemiology, in vivo and in vitro studies that have investigated the toxicity of biomass burning-derived PM have been identified and their results discussed in order to identify if the emission source influences the toxicity of PM. This information will be used to inform whether biomass burning derived PM is likely to elicit similar adverse health outcomes to that observed for urban (e.g. traffic-related) PM. The experimental design of existing studies will also be critically appraised and knowledge gaps identified in order to inform the direction of future research.

\section{Methodology}

We performed a narrative review of the literature to synthesise current epidemiological and toxicological evidence relating to the health impacts of PM emitted from biomass burning. In order to identify relevant scientific papers, a search of PubMed was performed using keywords such as 'Biomass burning' AND particulate matter OR 'PM10/2.5' OR ultrafine particles OR air pollution AND 'toxicity' OR 'hazard' AND 'in vitro' OR 'in vivo' OR 'epidemiology' OR 'human health'. The abstract of each paper that was identified from the search was read to identify the relevance of the publication to our review. In addition, research publications that were referenced in these articles or in relevant review articles but were not identified in the PubMed search were also considered if their content was deemed relevant to the review. The quality of each study was assessed by appraising the suitability of the experimental design, presentation of results and appropriateness of conclusions.

\section{Epidemiology Studies}

Large-scale epidemiological studies, beginning with the Harvard Six Cities study [1] and the seminal American Cancer Study [7], have consistently documented that elevated levels of PM are linked to detrimental health outcomes associated with short- and long-term exposure (reviewed in, e.g. [8-14]). There is also a growing body of evidence from epidemiology studies that suggests exposure to non-traffic-derived $\mathrm{PM}$, including industrial emissions and natural dust and salts, can cause adverse health effects (e.g. [67, 68]).

Epidemiology studies to assess whether exposure to biomass burning-derived PM is linked to a similar set of health outcomes as traffic PM were identified and their results are summarised in Table 1. Available studies have primarily focussed on investigation of negative impacts of biomass burning-derived PM on the respiratory and cardiovascular system (e.g. increased exacerbations of asthma and COPD, hospital admissions, use of medication, mortality, respiratory infections, stroke and myocardial infarction incidence) (reviewed in $[11,13,78])$, with a more limited number of studies assessing impacts on other adverse health effects (e.g. adverse birth outcomes).

The majority of epidemiology studies investigating the toxicity of biomass burning-derived PM have focussed on health impacts associated with exposure to PM during wildfire events. For example, Rappold et al. reported an increase in hospital admissions for cardiopulmonary disease (e.g. asthma, COPD, pneumonia, heart failure) during a peat wildfire event in North Carolina, USA [73]. Similarly, Morgan et al. identified an association between the levels of bushfire PM and respiratory hospital admissions in Sydney, with a 3.8\% increase in admissions for asthma and 5\% increase for COPD observed with a $10-\mu \mathrm{g} / \mathrm{m}^{3}$ increase in bushfire PM [72]. A systematic review of 61 epidemiology studies investigating non-occupational exposure to wildfire smoke demonstrated that $>90 \%$ of the studies found significant positive associations with respiratory morbidity [79]. In occupational studies, wildland firefighters have shown a consistent trend of declines in forced expiratory volume in $1 \mathrm{~s}$ (FEV1) following the forest fire season, with some indication of a return to baseline FEV1 levels [80]. Furthermore, Swiston et al. demonstrated that acute exposure to woodsmoke (from forest fires in Canada) was associated with pulmonary and systemic inflammation in firefighters [70]. Wildfire smoke-haze episodes were found to raise levels of circulating neutrophils in the blood of exposed national service men in Singapore [69]. The effect of smoke from wild and prescribed biomass burning on human health is a complex framework of interrelations and trade-offs, as described by Williamson et al. [81]. For example, exposure to smoke from biomass burning (e.g. wildfires) can occur at low frequency and can potentially affect large areas and populations, whereas prescribed agricultural burning affects smaller areas but occurs more often. Furthermore, prescribed fires often avoid hot and windy conditions, which can result in smoke getting trapped under atmospheric inversions or transported over urban areas and thereby increasing ambient concentrations and population exposure.

Cardiovascular morbidity in relation to wildfire smoke has been reviewed by Reid et al. [82], with the conclusion that results, at present, are inconsistent. Many epidemiology studies have not found any associations between wildfire smoke exposure and grouped cardiovascular disease (CVD) outcomes. Specific endpoints, such as out-of-hospital cardiac arrests and hospitalisations for acute myocardial infarction, were associated with biomass-related PM in selected studies [73, 76, 77]. Studies investigating ischemic heart disease (IHD) morbidity (e.g. hospitalisations/emergency department visits related to IHD) associated with wildfire smoke exposure also showed inconsistent results, and there were only a limited number of studies for other CVD outcomes [82].

Adverse birth outcomes due to wildfire smoke exposure during pregnancy are plausible [82], with studies finding 


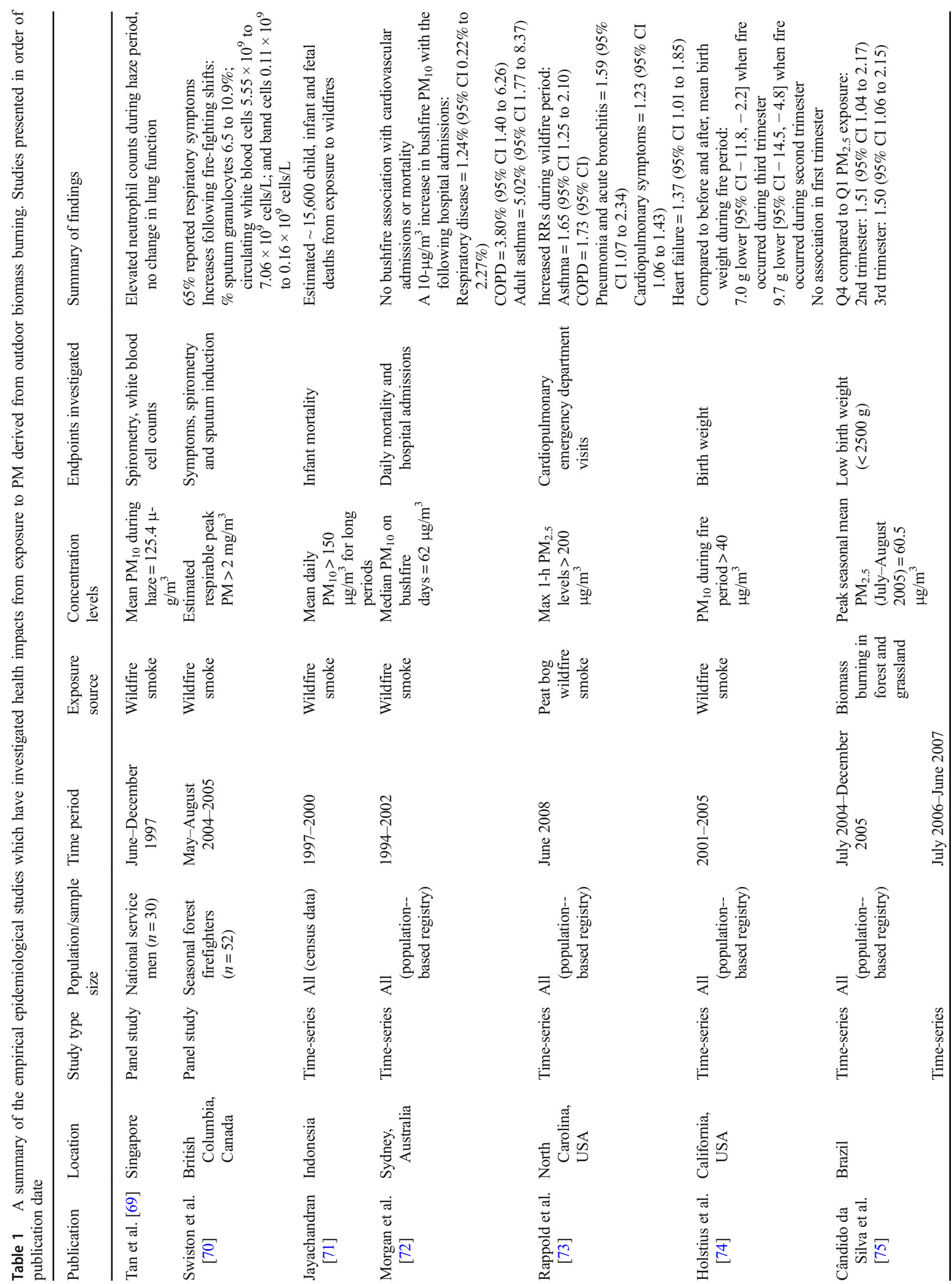


associations between wildfire or agricultural burning smoke and early life death [71], lower birth weight [74, 75], and small for gestational age [83]. However, currently available evidence for causation from biomass burning emissions is limited.

Whilst much of the epidemiology on biomass burning has focussed on high exposure scenarios (e.g. associated with wildfires), another body of literature focusses on indoor biomass burning for cooking and heating. Evidence is accumulating linking household air pollution due to biomass cooking or heating fuels and adverse birth and pregnancy outcomes [84]. Smith et al. performed a critical review of the literature and observed that there was an increased incidence of acute respiratory infections in children in developing countries due to indoor biomass burning [85]. Indoor biomass burning for cooking or fuel can increase PM levels to $20-80 \mathrm{mg} / \mathrm{m}^{3}$, presenting significant risks for women at home for COPD and lung cancer [86].

Taken together, the findings from epidemiology studies suggest that exposure to biomass burning-derived PM can cause adverse health effects. Existing studies have primarily focussed on investigation of impacts on the pulmonary and cardiovascular systems, and the findings have revealed that biomass burning derived PM causes adverse health outcomes which are similar to those observed for traffic-derived PM (outlined in Fig. 1). However, it would be beneficial to better characterise exposure-response relationships with these health outcomes, to refine comparability with urban PM. Also, it would be helpful to consider the impact of biomass burning derived PM on a wider range of adverse health outcomes in the future (e.g. neurological and metabolic diseases). Furthermore, to date, the majority of epidemiology studies have considered the impacts of PM derived from wildfire events on health, with relatively fewer studies investigating the toxicity of other biomass sources. Therefore, future studies should consider how other sources of biomass burning can impact on health.

\section{In Vivo Studies}

In vivo (rodent) studies have been performed to identify whether the emission source influences the toxicity of PM. A summary of the experimental design and main findings of the in vivo studies that have been conducted to date to assess the toxicity of biomass burning-derived PM is presented in Table 2.

The PM samples tested in existing in vivo studies are diverse. Several studies have compared the pulmonary toxicity of ambient PM samples obtained from different sites and seasons in order to identify whether different PM emission sources cause differential toxicity (e.g. [88, 91, 95]). Seasonal differences in the toxicity of ambient PM are investigated as the emission source is likely to vary throughout the 
year (e.g. more biomass burning is expected in homes in winter months). Of interest is that when ambient PM samples are tested, these are mainly derived from EU and US locations, and thus, testing samples from a wider array of locations is recommended to understand the global relevance of the findings obtained to date. For example, the samples tested to date include wood burning from wildfires or heating, but in SE Asian countries, such as Thailand, biomass burning also includes agricultural burning of crop residues and fires from different types of vegetation. As the type of fuel burned may be a determinant of biological effects, and atmospheric conditions may impact the composition and toxicity of the samples, we may not be able to extrapolate effects from European and American samples to Asia. PM from the burning of different types of biomass has also been generated in the laboratory and its toxicity assessed in vivo (e.g. [49, 87, 92, 96]). In addition, the toxicity of PM samples emitted when cooking with biomass as a fuel source has been tested in one study [94]. Finally, PM has been collected during wildfire events to better understand the potential detrimental impacts of wildfires on health (e.g. [52, 89, 92]).

Taken together, the results of existing in vivo studies suggest that biomass burning derived PM can elicit toxicity to the lung, but that PM samples from different biomass sources vary in their toxic potency. In addition, PM samples derived from traffic sources are typically more toxic than biomassderived PM samples. However, not all in vivo studies conducted to date have included a traffic PM sample and instead are more focussed on comparing the toxic potency of different types of biomass sources. We therefore suggest that in the future, when performing in vivo studies that investigate the toxicity of biomass burning-derived PM a sample which represents urban/traffic-derived PM should be included as this helps to identify whether biomass-derived PM has a similar toxic potency and will elicit similar adverse health outcomes.

Interestingly, despite differences in the experimental design employed across the different in vivo studies performed to date (e.g. species/strain of animal selected, PM source, PM sampling procedure, administration route, PM dose, time point and endpoints assessed), there is evidence that similar biological responses are activated in the lung in vivo following exposure to biomass derived PM. More specifically, activation of inflammation is commonly observed following pulmonary exposure to biomass burning derived PM samples of diverse sources, including biomass burning (Table 2). Investigation of pulmonary inflammation is prioritised for investigation in vivo as it is established that inhaled PM can activate a pulmonary inflammatory response which is likely to drive its adverse health impacts, as previously discussed. However, assessment of the involvement of oxidative stress in the toxicity of inhaled biomass burning derived PM has not been routinely assessed in existing in vivo studies. This is surprising as existing knowledge suggests that oxidative stress also plays a key role in PM toxicity (e.g. [97]). Therefore, whilst reactive oxygen species (ROS) production and antioxidant depletion have been assessed in some studies, a more comprehensive investigation of whether biomass PM stimulates oxidative stress is required in the future. More specifically, employing a battery of tests which assess ROS levels, antioxidant levels/activity, oxidant-mediated damage, and the ability of antioxidants to protect against PM-mediated toxicity can aid in unravelling the role of oxidative stress in PM toxicity [66]. This will help identify whether similar adverse health impacts are expected for biomass burning-derived $\mathrm{PM}$ as those known for traffic-derived PM.

Investigation of impacts of biomass burning-derived PM on the lung has been prioritised in existing studies, as the main route of exposure to PM is inhalation. However, only a limted number of inhalation studies have been performed to date (e.g. $[87,96])$, with intratracheal instillation/oropharyngeal aspiration being most commonly employed as the route of administration (Table 2). This is not surprising given the expense of performing inhalation studies and requirement for specialised equipment and larger quantities of PM. Of interest is that Kim et al. [96] exposed mice to biomass PM from different fuel sources obtained during different phases of combustion via inhalation, and their findings aligned to those observed following oropharyngeal aspiration [49, 92]. However, ideally, it would be beneficial to conduct more inhalation studies as administration via this method is more physiologically relevant than other approaches. Furthermore, short- and long-term exposure of humans to biomass PM is expected. To date, the majority of studies have acute responses in rodents following a single administration of biomass PM at one time point, and few studies have investigated the toxicity of biomass burningderived PM following repeated exposures (e.g. [91]). Therefore, there is a need to perform chronic in vivo studies which encompass repeated and longer-term exposure to biomass burning-derived PM to address this knowledge gap. It would also be beneficial to consider other target sites in future studies, as inhaled particles can stimulate systemic effects to promote the initiation and progression of disease in extrapulmonary organs (e.g. reviewed by Stone et al. [36]).

To summarise, the findings from in vivo studies conducted to date suggest that biomass burning derived PM can stimulate pulmonary toxicity. The majority of studies have used inflammation as an indicator of toxicity and demonstrated that biomass burning-derived PM can stimulate an acute inflammatory response. There is also evidence that biomass derived PM can stimulate oxidant-driven responses; however, this endpoint is less routinely assessed. Several PM samples that represent different biomass sources are often tested in each study, with the findings suggesting that the biomass type can influence the toxicity of the emitted PM. Furthermore, when comparative studies are performed, traffic derived PM is often identified as being more toxic than biomass burning derived 


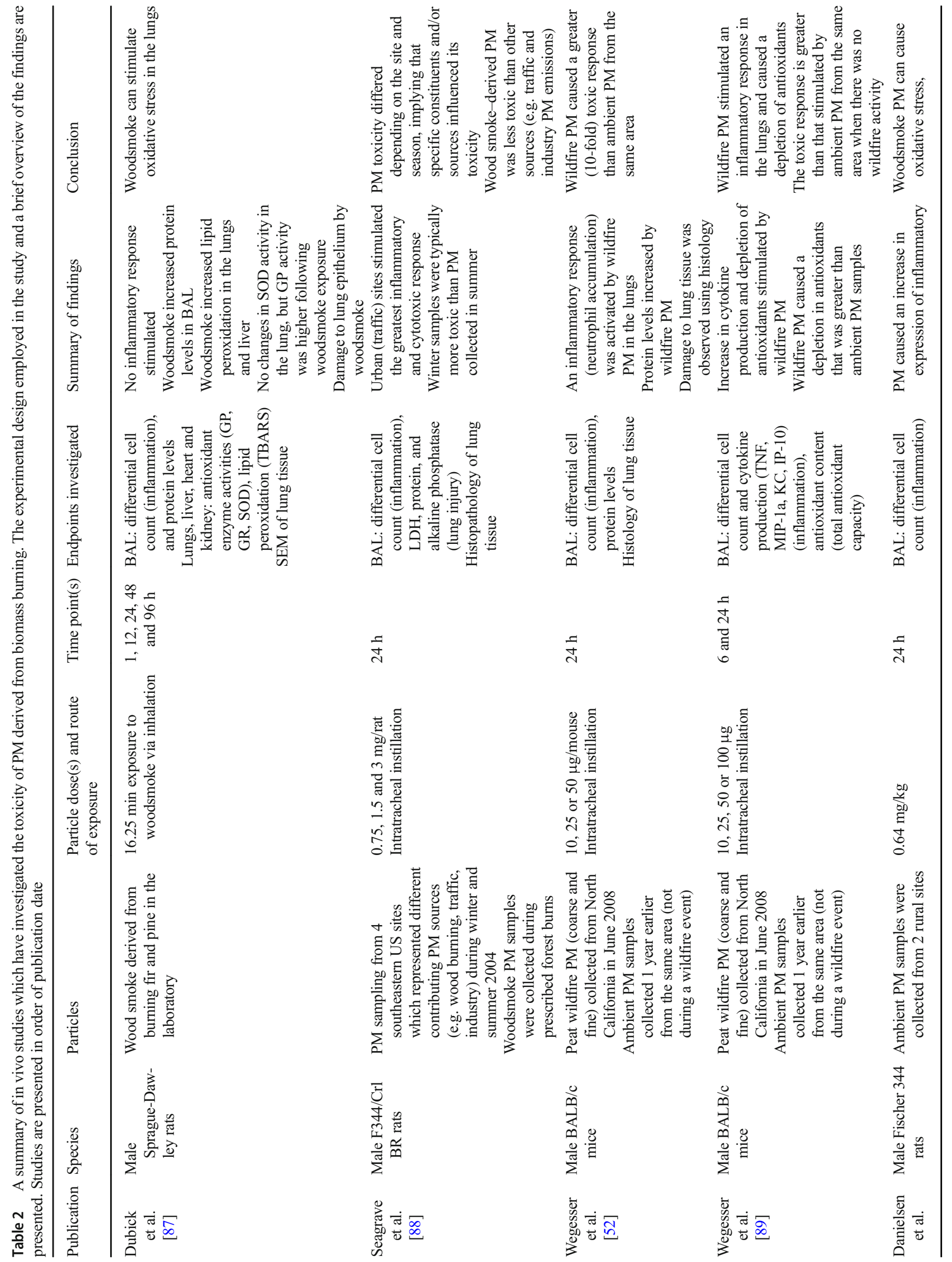




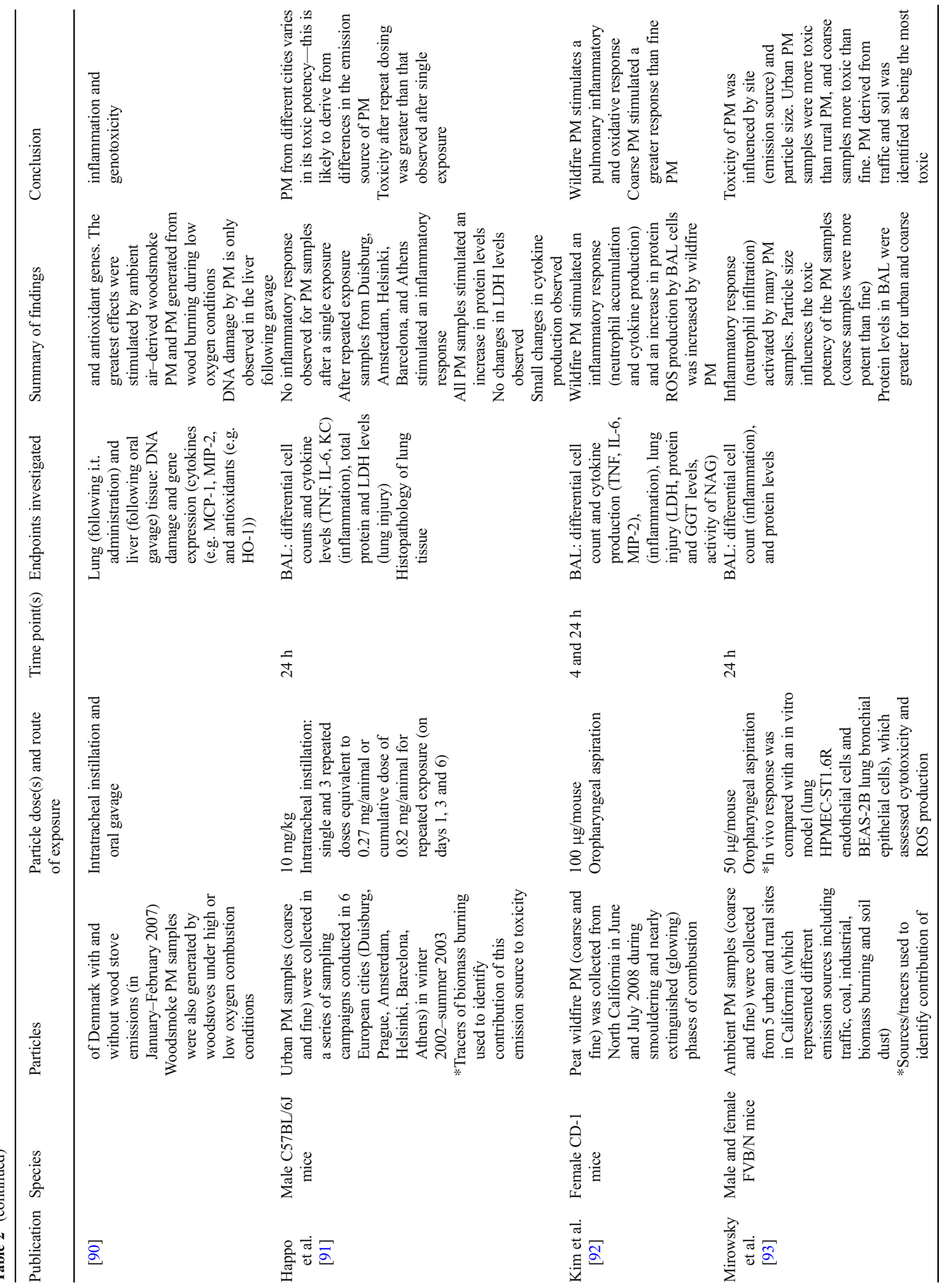




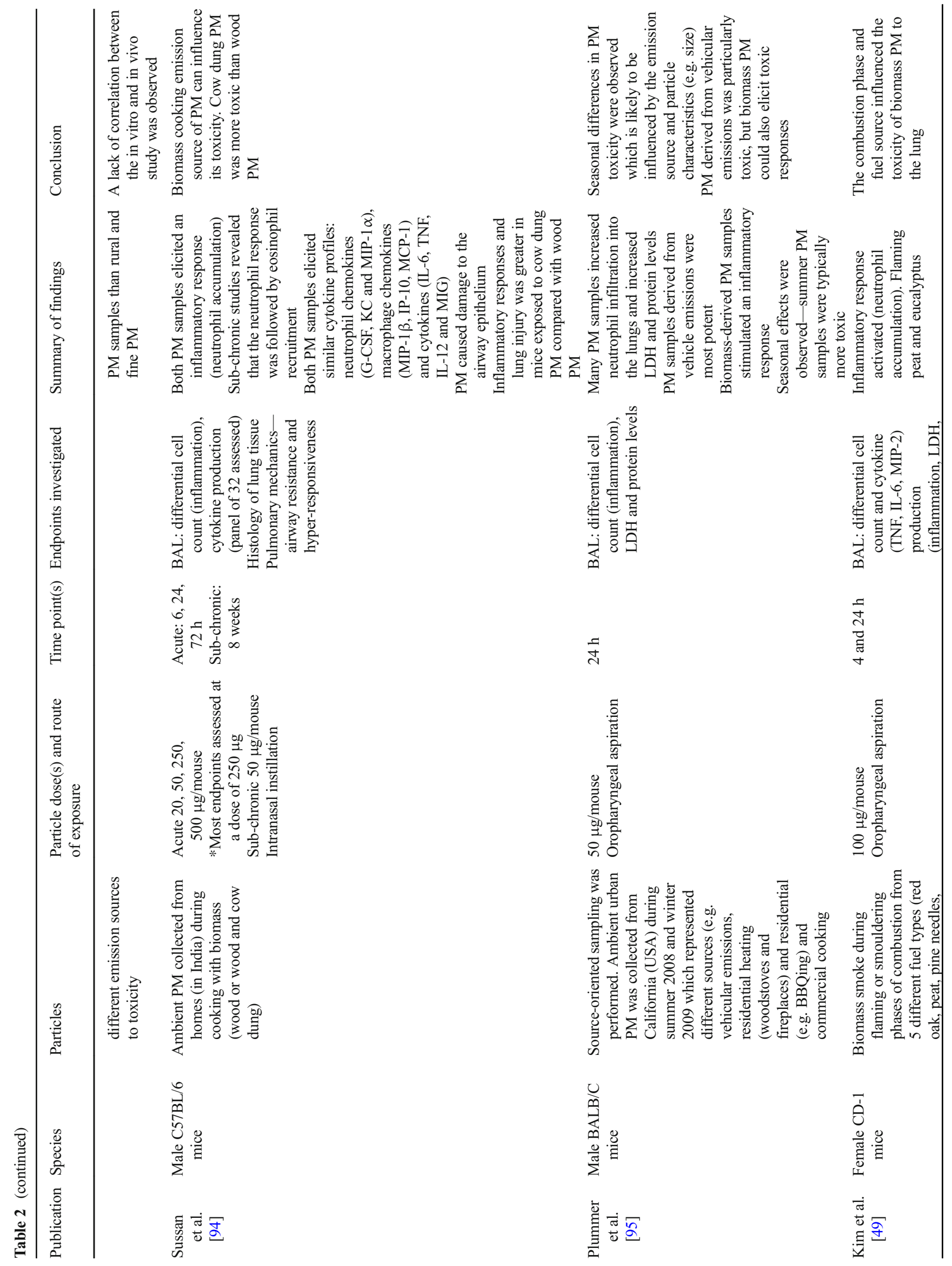




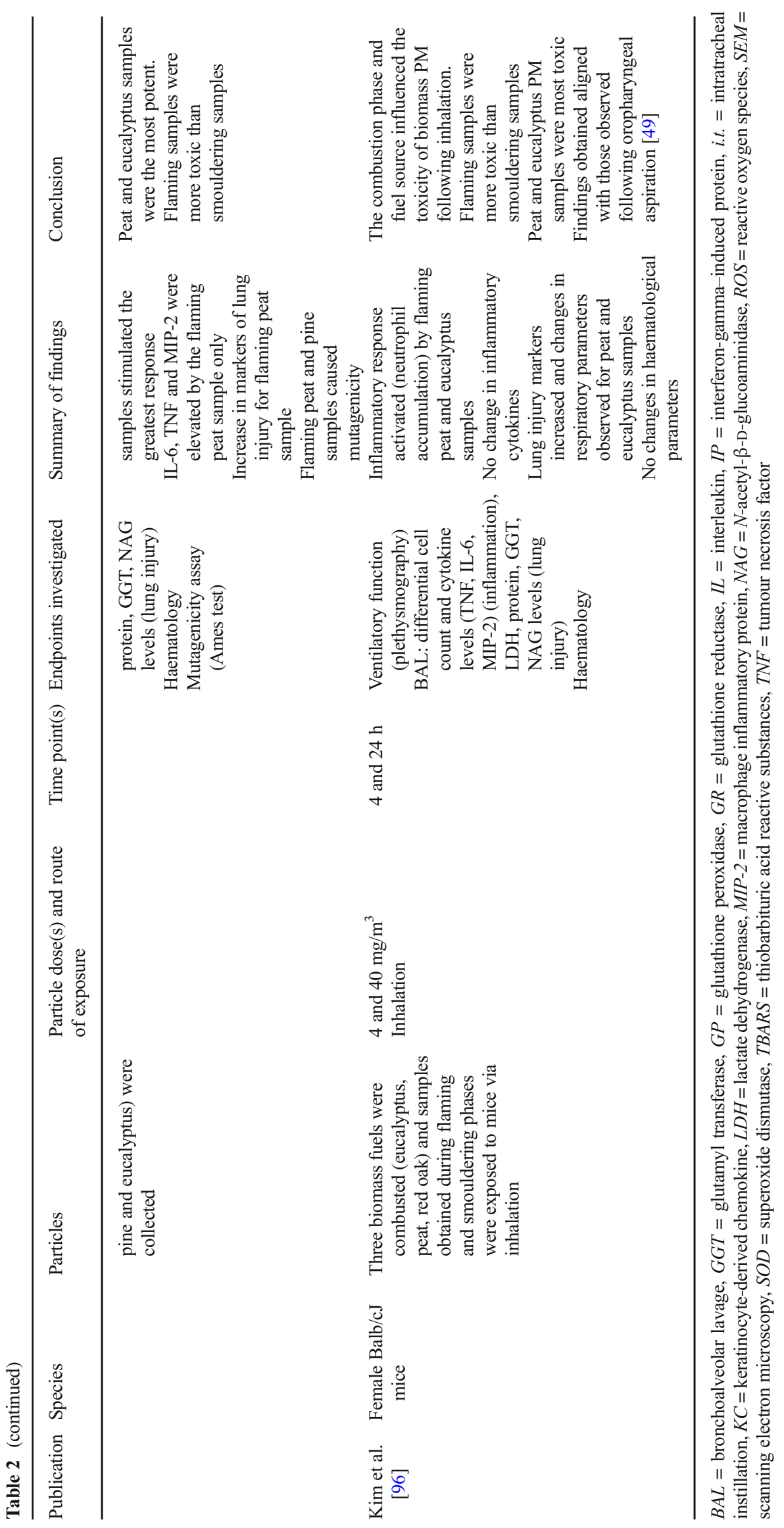


PM. There are gaps in knowledge that need to be addressed in order to gain a better understanding of the toxicity of PM in vivo. In particular, it is advised that longer-term, repeat dose studies are prioritised as to date, and studies have typically investigated acute responses following a single administration of PM at one dose.

\section{In Vitro Studies}

There is a drive to reduce the use of animals when performing toxicology testing, and thus, it is prudent to consider if in vitro models can be used as an alternative to rodent testing to predict PM toxicity. Table 3 summarises the experimental design and findings from in vitro studies that have investigated the toxicity of PM derived from biomass burning.

To help identify the contribution of different emission sources to the adverse health effects of ambient PM, the toxicities of PM samples obtained from different sources have been compared in vitro. For example, ambient PM samples have been collected from different locations and seasons that reflect different emission sources (e.g. [90, 100, 102, 103, 108, 109, 111, 113]). Alternatively, biomass PM samples have been generated in furnaces in the laboratory and their toxicity assessed in vitro (e.g. [98, 106, 107, 110, 112, 114]). Finally, PM samples have been collected during wildfire events and their toxicity assessed in vitro [111-114]. As with in vivo studies, for comparative purposes, studies often, but not always, include PM samples collected from urban locations (e.g. to represent traffic derived PM) in order to identify whether the toxicity of PM from different sources is comparable.

Existing studies have focussed on assessing toxicity to the lung via investigation of responses of bronchial and alveolar epithelial cell lines (e.g. human Beas-2B and A549 cell lines) and macrophages (e.g. RAW264.7 (mouse) and THP-1 (human) cell lines). The cell types selected are relevant as PM is likely to interact with these cells following inhalation. Of benefit is that cells of human origin are frequently used in in vitro studies. However, to date, monocultures of cells have typically been used when investigating PM toxicity in vitro. Advanced in vitro 3D co-culture models are available that better represent the physiology of the lung (e.g. [115]), and therefore, it is recommended that these models are used more widely to assess PM toxicity in the future.

The findings from existing studies indicate that biomass burning derived PM can elicit toxicity in vitro (Table 3); however, there is a lack of agreement regarding whether the toxic potency of biomass burning derived PM is greater than that observed for other emission sources (e.g. traffic). The discrepancies observed between studies are likely to derive from differences in the experimental design employed, which are described in more detail below.
The sampling procedure used for PM collection may account for differences in the toxic potency of PM investigated between studies. Furthermore, the samples selected for investigation are very variable (e.g. use of laboratory generated vs ambient sources, fuel selected for biomass and combustion procedure used (e.g. furnace used, burning time, phase of burning when PM was collected)) which can influence their toxic potency. Of interest is that existing studies have primarily assessed the toxicity of PM derived from wood burning and wildfires. The majority of wildfire samples tested to date have come from one source: PM derived from peat wildfires in North Carolina in 2008. Of benefit is that the toxicity of these samples has been extensively tested across epidemiology, in vivo and in vitro studies (see below). However, ideally the toxicity of PM samples collected from wildfire events associated with the burning of different types of biomass would be tested. Such samples are not always available; thus, it is suggested that toxicity tests are performed which test the toxicity of biomass burning derived PM samples that are generated in the laboratory. This will help reveal the potential adverse health effects of more diverse types of biomass sources. In particular, it is noteworthy that there is a lack of studies which have assessed the toxicity of agricultural burning-derived PM, and this knowledge gap should be addressed in the future. Furthermore, the majority of existing (in vitro and in vivo) studies which have investigated the toxicity of environmental PM samples have been performed in the EU and US, and there is a lack of investigations of samples obtained from other countries. This is important as different emission sources are likely to contribute to PM emissions in different countries, and thus, a wider panel of ambient PM samples which reflects the global diversity of biomass burning should be considered in the future. In vitro studies not represented in Table 3 have assessed the toxicity of PM collected from different urban/traffic-derived and rural sources and frequently find seasonal differences in PM toxicity (e.g. [31, 32, 116]). As the toxicity of biomass burning-derived PM was not assessed in these studies, they are not discussed in-depth here. However, these studies provide additional evidence that the emission source can influence PM characteristics and toxicity.

The endpoints selected for assessment of toxicity, as well as the approaches used to assess the biological response of interest, may influence the toxicity of PM observed in vitro. Of benefit is that a range of endpoints are frequently assessed when investigating PM toxicity in vitro. By using a battery of approaches, a better understanding of the mechanism of toxicity can be gained to help identify potential adverse impacts on health. Interestingly, common markers of toxicity are assessed across in vitro studies, namely cytotoxicity, cytokine expression/production, oxidative stress (e.g. ROS production, antioxidant levels/activity, oxidant damage to proteins and lipids) and DNA damage. These endpoints have been prioritised due to existing knowledge regarding the 
mechanism of PM toxicity to the lung, as the activation of inflammation and oxidative stress is key to its ability to elicit adverse health outcomes (e.g. [35, 36, 70, 117]). Existing studies have shown that biomass PM can elicit toxicity via the same mechanism to traffic-derived PM (Table 3). This suggests that the detrimental impacts on health that have been widely studied for traffic PM may be applicable to biomassderived sources. It is noteworthy that different experimental approaches can be used to assess each endpoint of interest and that a consistent approach was not used across studies for each individual endpoint. This is important when making comparisons between studies as the different approaches used to assess the same biological response may vary in their sensitivity. Standardisation of protocols for assessing specific outcomes using particular methods would therefore improve our ability to compare toxicity of different types of PM.

The concentrations of PM and time points tested are variable across in vitro studies. Ideally, a range of PM concentrations would be tested in each study in order to generate doseresponse curves, but on several occasions, only one particle concentration is tested. It is therefore recommended that several PM concentrations are tested in each study. The two most commonly used dose metrics are $\mu \mathrm{g} / \mathrm{cm}^{2}$ or $\mu \mathrm{g} / \mathrm{mL}$. On some occasions, but not always, researchers express the particle concentration in both ways, which allows comparisons of PM toxicity to be made between studies. There is debate regarding how particle concentration should be expressed in vitro, and other dose metrics may also be relevant (e.g. surface area) $[118,119]$. In vitro studies performed to date have focussed on assessing toxicity following a single exposure, with cell responses typically assessed at $24 \mathrm{~h}$ post-exposure. There are fewer longer-term studies which have assessed PM toxicity following repeated exposure, and it is recommended that this knowledge gap is addressed in the future, as this would be more representative of how people are really exposed to biomass-derived PM.

The endpoint being investigated often dictates which time points are selected in each study. For example, earlier time points (e.g. 2-4 h) may be selected to investigate cytokine gene expression, whereas longer time points (e.g. 24 h) are often selected when assessing cytokine production. However, consistent time points are not used between different studies for the same markers of toxicity which makes it difficult to make comparisons between studies. Of interest is that investigation of toxicity of PM to the lungs has been prioritised in studies performed to date, but it would be beneficial to investigate PM toxicity to a more diverse range of target sites in vitro (e.g. cardiovascular system, liver, CNS).

To summarise, the results of in vitro studies performed to date suggest that biomass burning-derived PM can elicit toxicity to the lung. Existing studies have consistently demonstrated that that biomass burning-derived PM can activate inflammatory, oxidative and genotoxic responses. As this aligns with the mechanism of toxicity of traffic PM, it is suggested that biomass-derived PM may stimulate similar adverse health impacts (outlined in Fig. 1). However, it is evident that the PM source can influence its toxicity potency and thus not all biomass sources will emit PM that is equally toxic. In the future, a greater diversity of biomass-derived PM samples needs to be assessed within in vitro studies.

\section{In Vivo Versus In Vitro Models}

Of benefit is that some studies have investigated the toxicity of the same biomass burning derived PM samples across different experimental models. For example, epidemiology, in vivo and in vitro studies have been performed with PM samples obtained from the same wildfire event in North California in June 2008, with pulmonary and cardiovascular toxicity observed across all models used [52, 73, 89, 92, 104, 105]. Briefly, epidemiology studies identified that an increase in hospital admissions (for respiratory disease (e.g. asthma, COPD, infectious disease) and heart failure) was observed during the time of this wildfire incident [73]. In vitro and in vivo studies demonstrated that wildfire PM could elicit toxicity via inflammation and oxidative stress. Therefore, there was agreement across models that wildfire PM could elicit adverse health effects.

However, the findings from in vitro and in vivo studies which investigate biomass burning derived PM do not always agree. For example, Mirowsky et al. assessed the toxicity of ambient PM samples from urban and rural sites in California (which represented different emission sources) in vivo (mice exposed via oropharyngeal aspiration) and in vitro (pulmonary endothelial and bronchial epithelial cells). The in vivo studies assessed whether PM samples activated inflammatory responses, and the in vitro studies investigated ROS production [93]. There was a lack of correlation between the in vitro and in vivo response. However, whilst oxidative stress and inflammation are linked, the endpoints being assessed in each model were not directly comparable, which may explain the lack of correlation between models. For example, it may have been more advisable to compare cytokine production in vitro with the in vivo inflammatory response.

Accordingly, it is recommended that more studies are performed that compare the response of in vitro and in vivo models to biomass burning-derived PM, to identify the limitations of each model and to inform what models should be prioritised when investigating PM toxicity in the future. Ideally, a tiered testing strategy would be employed in the future when assessing biomass burning-derived PM toxicity that promotes the use of alternative (non-rodent) models before progressing to animal testing. 


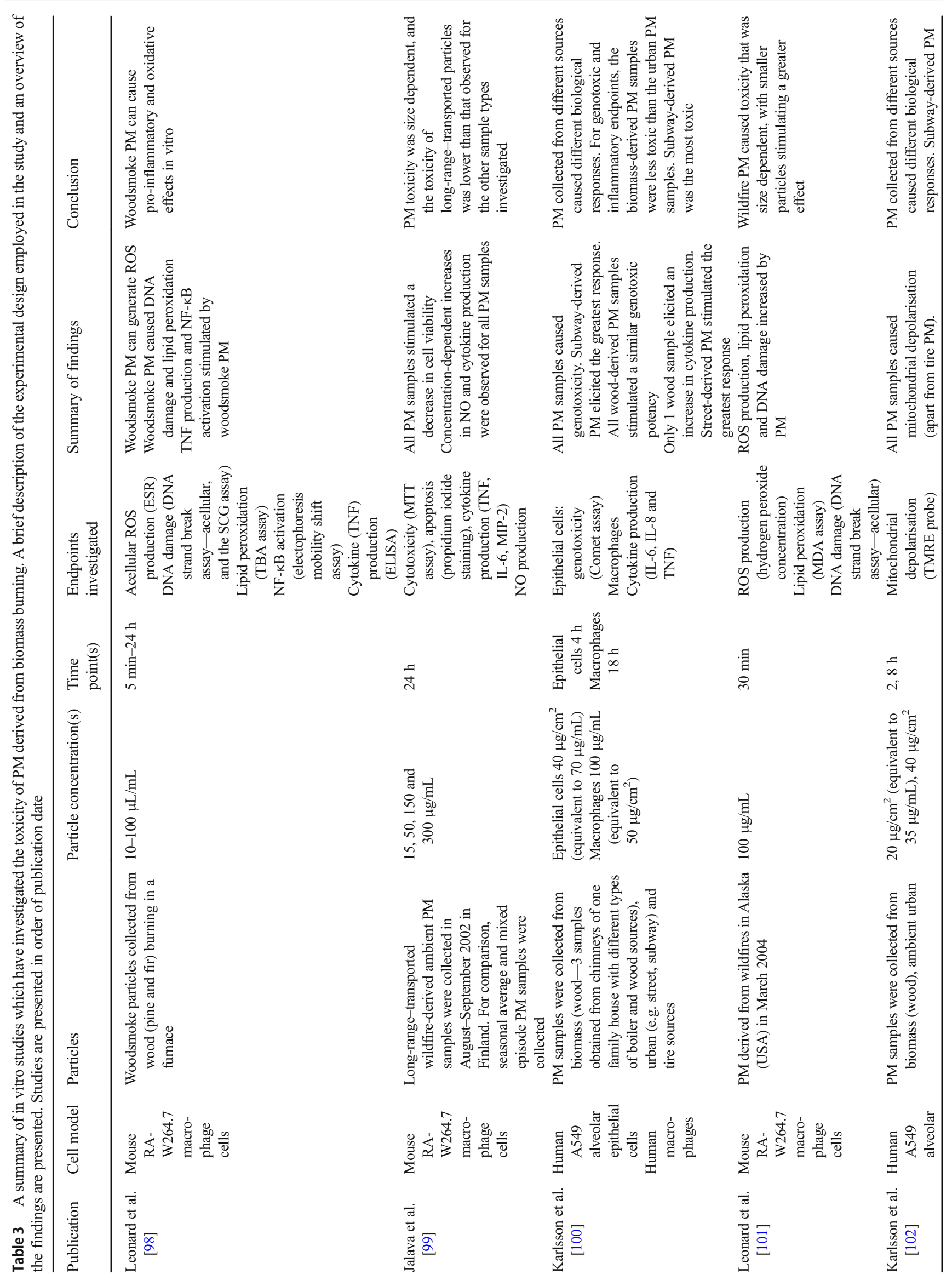




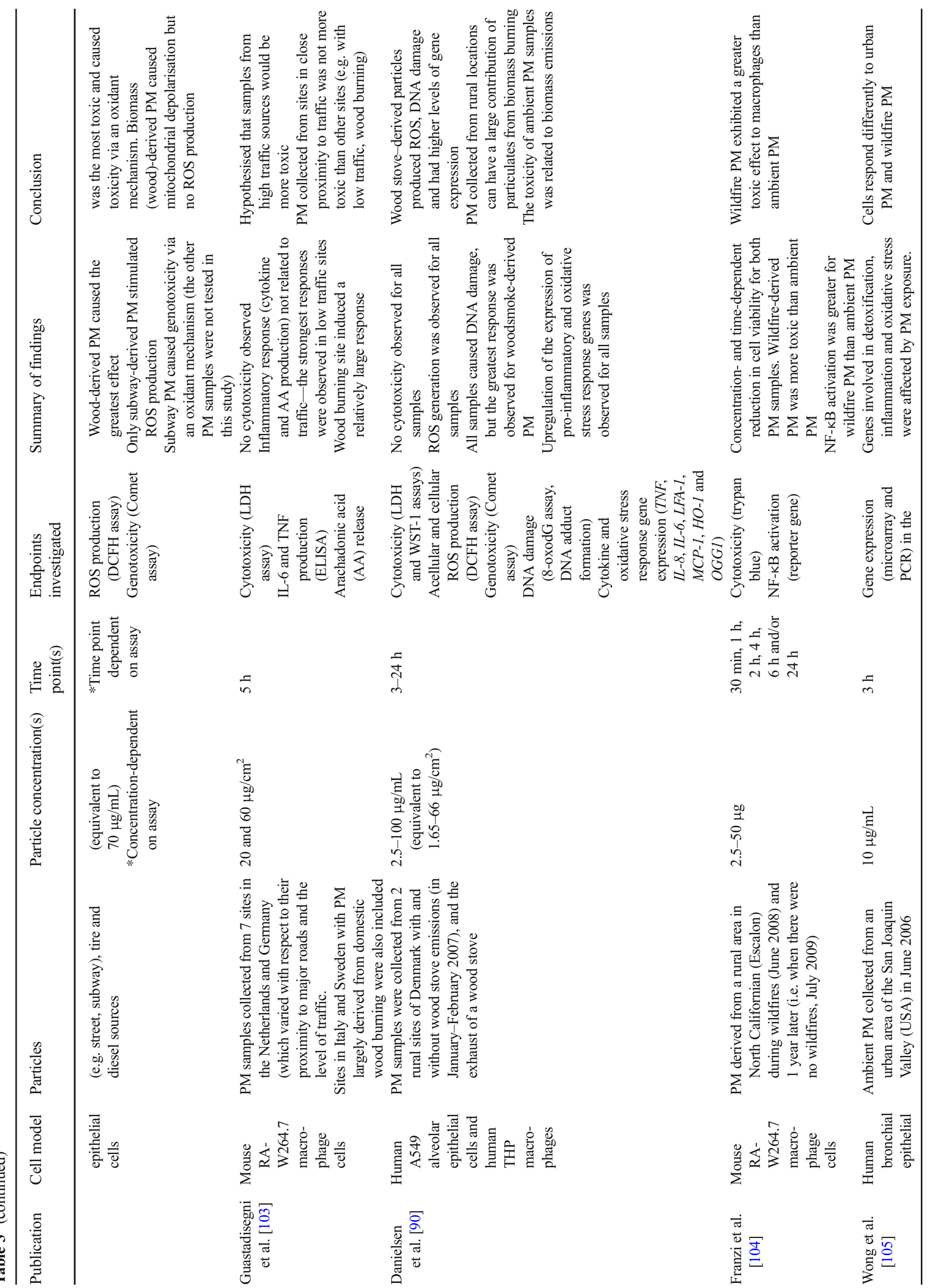




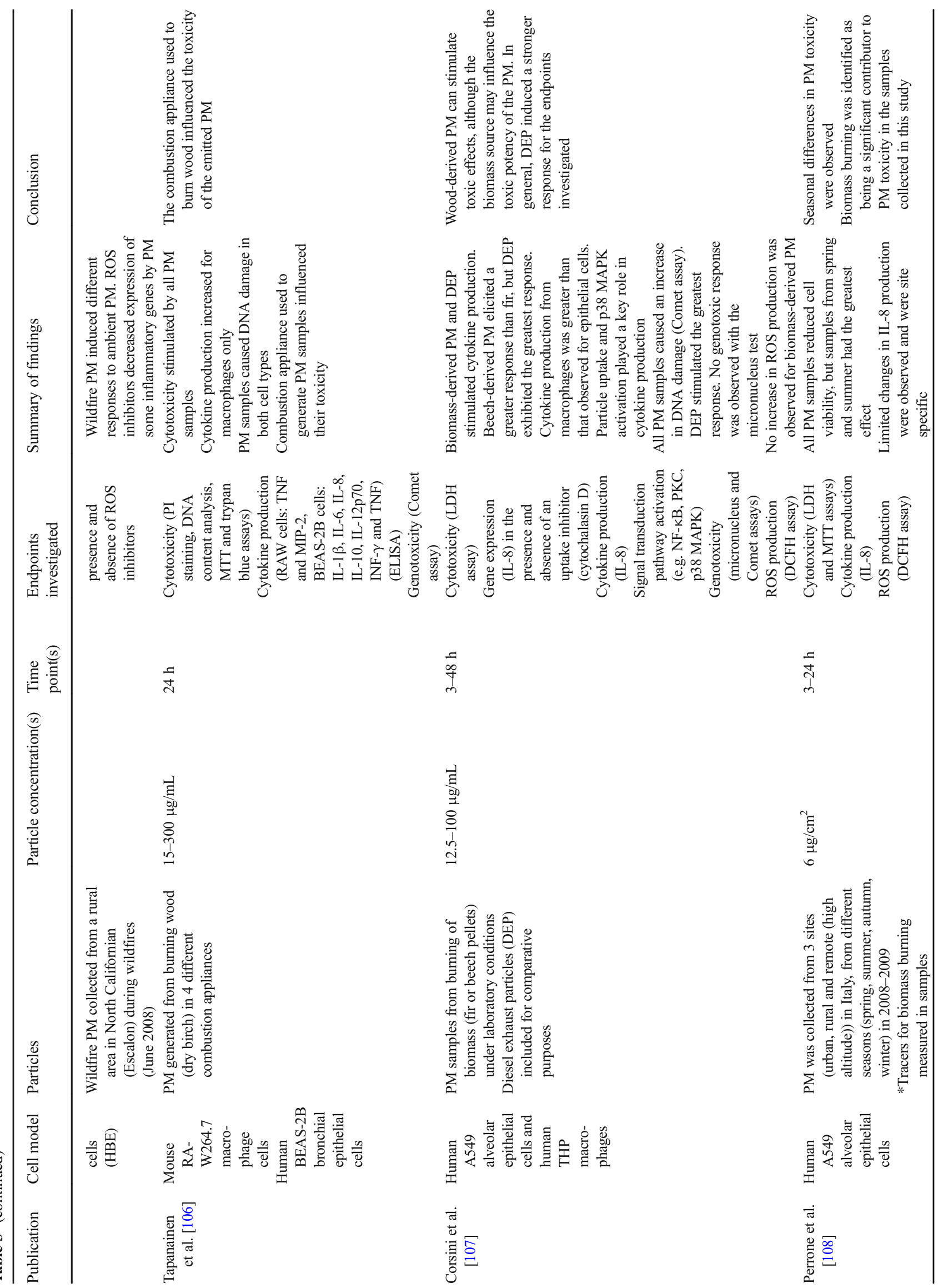




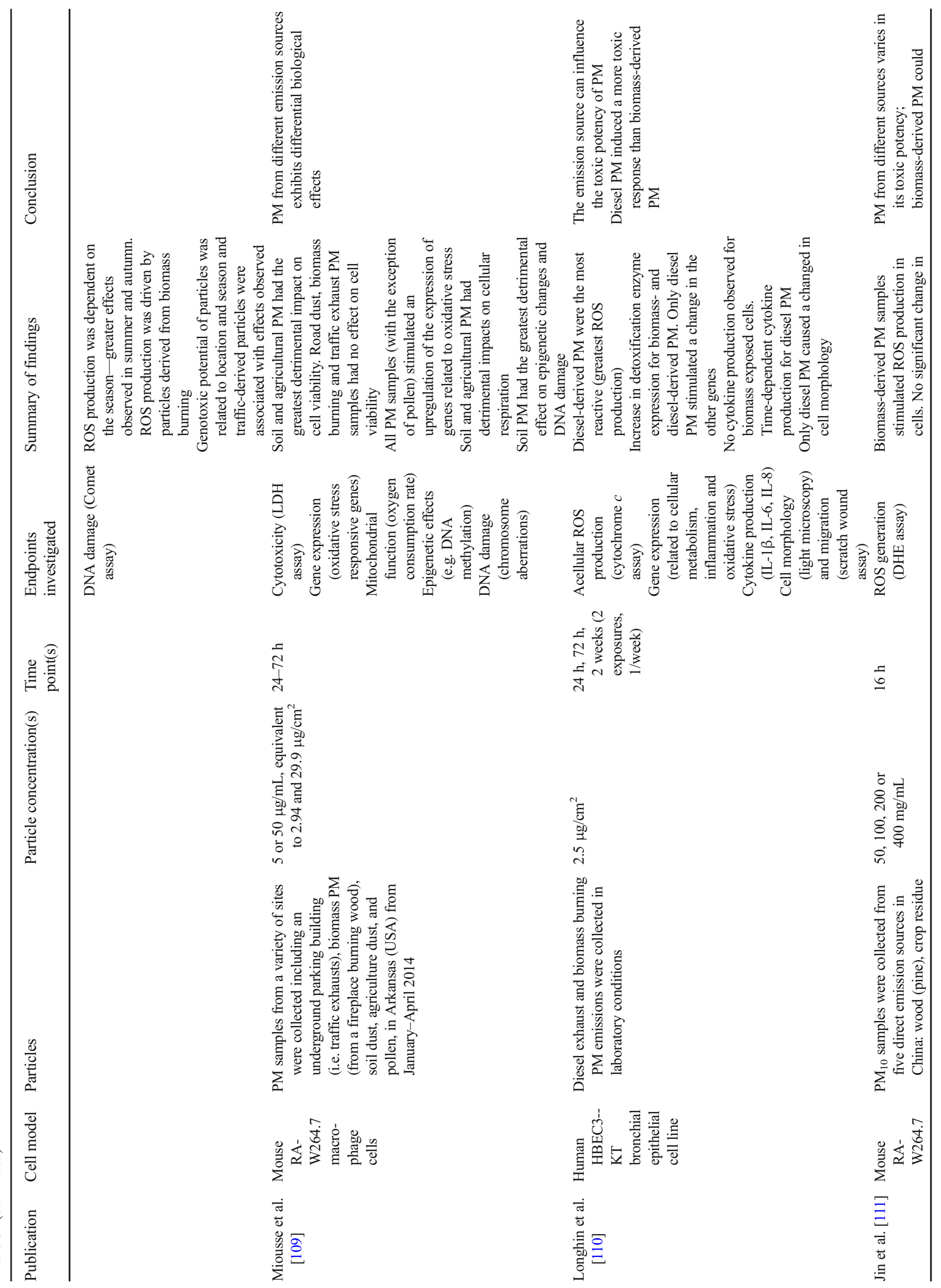




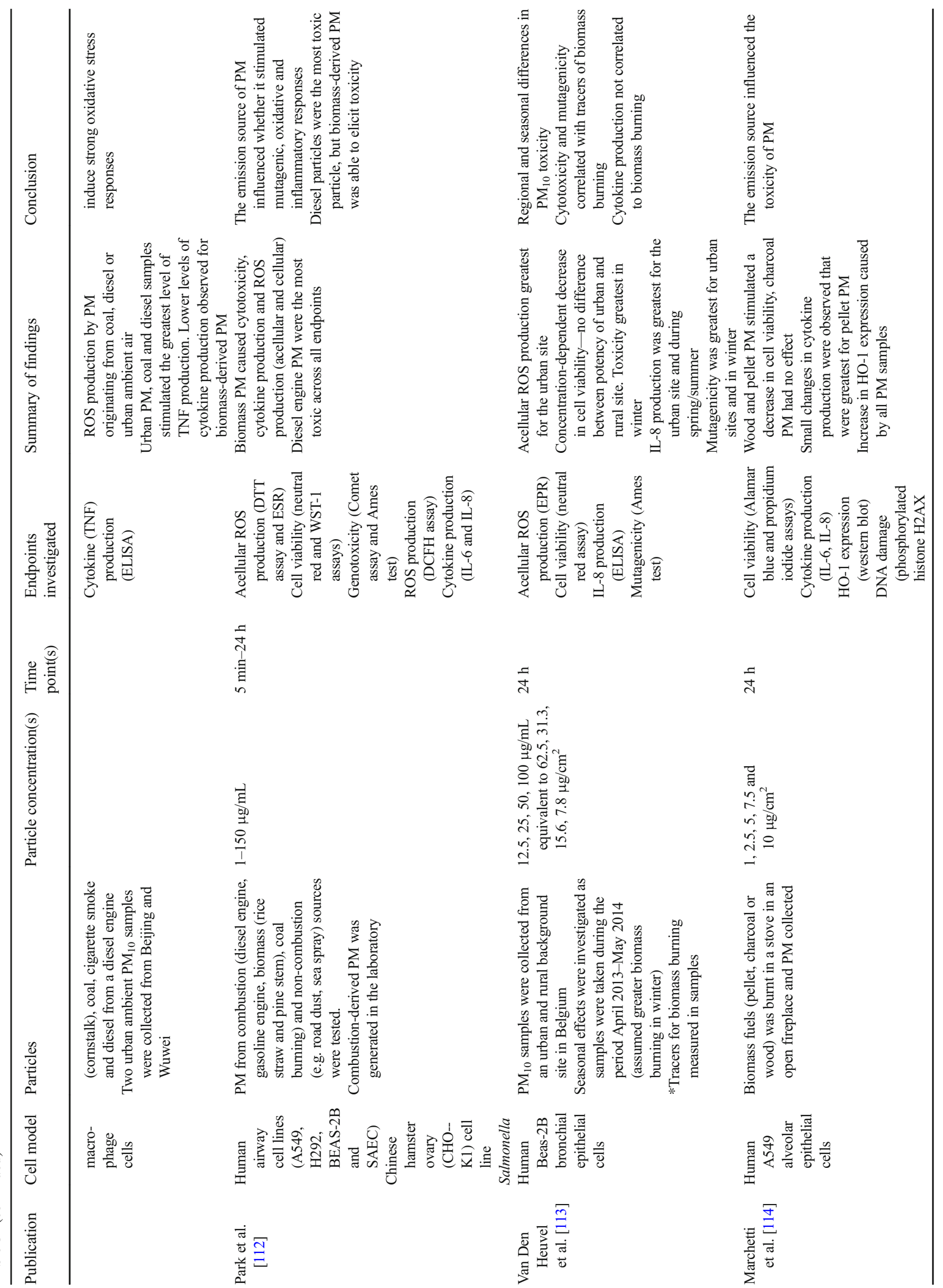




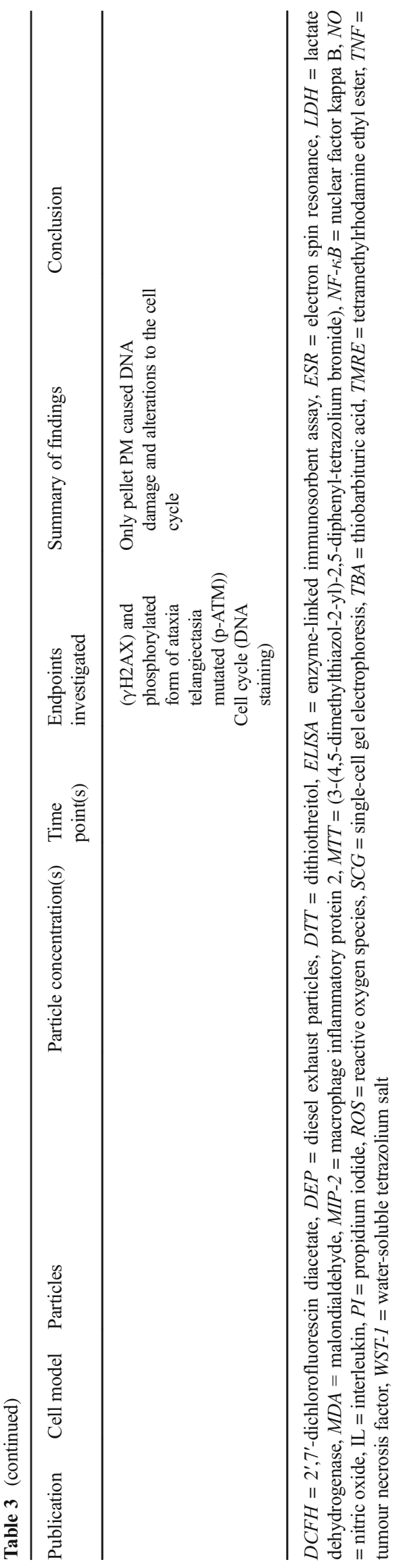

Toxicity of Biomass Burning Derived PM
in Thailand: Directions for Future Research

Exposure to PM emitted from biomass burning from many sources (e.g. domestic cooking and heating, wildfires, agricultural) is anticipated to increase in both developing and developed countries. There is a growing body of epidemiological and toxicological (in vivo and in vitro) evidence that demonstrates biomass burning derived PM can elicit adverse health effects and that the biomass source can influence its toxic potency. Existing experimental studies to date have typically focussed on impacts on the lungs and demonstrated that biomass derived PM can stimulate oxidative stress, inflammation and genotoxicity. Thus, it is likely that biomass-derived PM will stimulate similar adverse health outcomes to urban (e.g. traffic)-derived PM (outlined in Fig. 1), which is known to cause toxicity via similar mechanisms. However, more comparative studies, which assess the toxicity of biomass burning and traffic-derived PM, are required as it is still unclear as to whether urban derived PM is more or less toxic than biomass burning derived PM as inconsistent findings have been observed to date in the available literature. The discrepancies observed are likely to arise due to differences in the experimental design employed between studies. Of interest is that studies conducted to date have focussed on investigation of acute effects, thus longer-term, repeat dose studies are required to fill knowledge gaps. Furthermore, the toxicity of different sources of PM are often assessed at the same concentration in laboratory toxicity tests, but the duration and frequency of exposure to biomass burning derived PM can vary, depending on the source. In addition, concentrations of biomass burning derived PM in the environment (e.g. during wildfires) can be much higher than PM from other sources. Thus, investigation of the toxicity of biomass PM over a wider range of concentrations would be advisable when performing experimental studies. To date, a focus has been placed on investigating potential impacts of biomass PM on the lungs and CV system. However, there is emerging evidence that traffic-derived PM can negatively impact on other body systems, and thus, the ability of biomass-derived PM to cause wide ranging health effects requires consideration in the future.

The toxicology studies that have been conducted to date on biomass burning-derived PM can help infer potential health impacts associated with biomass burning in Thailand. However, in order to better understand the health implications of biomass burning in that country, more research is required, and we advocate that this should encompass epidemiology studies, as well as experimental studies. In particular, there is a lack of epidemiology studies which have investigated the health impacts of different sources of biomass burning-derived PM in SE Asia. Accordingly, it would be beneficial to identify whether agricultural burning episodes elicit similar 
adverse health impacts to those associated with traffic air pollutants. Such studies should encompass consideration of different regions in Thailand and be performed over different seasons to capture different factors which may influence the toxic response (e.g. the biomass source being burnt including, for example, the type of crop being burnt, and whether forest or agricultural land is being burnt, and whether burning is performed pre- or post-harvest). Undertaking epidemiological studies examining well-established health impacts with traffic-related PM during the burning periods would help better understand which health impacts may be associated with PM emitted from biomass burning-derived sources. Such findings could also help provide more precise estimates in health impact assessments from medium- to longer-term exposure at a population level in Thailand. For experimental studies, there is a need to better capture PM sources that are relevant to Thailand in toxicology studies. This could be achieved via the collection of ambient PM samples from a variety of locations in Thailand which represent different emission sources of biomass burning-derived PM. For example, it is recommended that samples should be taken during haze and non-haze periods for comparative analysis of both PM physico-chemical characteristics and PM toxicity and, ideally, in concert with an epidemiological study. It is also advised that the toxicity of these biomass-related PM samples should be compared to traffic-related PM samples collected in Thailand. To better understand whether specific types of biomass have differential toxicity, PM samples could also be generated in the laboratory, by burning biomass samples that are relevant to Thailand (e.g. Bambusa vulgaris, Echinochloa crus-galli, Tectona grandis, Diptero carpusalatus, Zea mays, Oryza sativa, Dimocarpus longan, and Litchi chinensis [120]) and testing the toxicity of the emitted PM in vitro and in vivo.

\section{Conclusion}

There is currently a drive to reduce the level of ambient PM (globally) to improve air quality and protect human health. However, assessment of air quality does not currently distinguish between the varied toxicity of PM from different sources. Epidemiology, in vivo and in vitro studies have consistently demonstrated that biomass-derived PM can elicit toxicity. Consideration of the properties of PM which confer toxicity was out with the scope of this review but has been discussed previously (e.g. [10]). It is likely that differences in the toxic effects of PM emitted from different sources/ locations derive from differences in the properties of the emitted particles (e.g. particle size (and surface area) and composition (e.g. PAH, metal and endotoxin content)). Therefore, a better understanding of how the emission source influences the toxicity and physico-chemical properties of PM, as well as exposure patterns, could better inform intervention strategies to improve air quality. This will require that a thorough assessment of the physico-chemical properties of PM is performed in parallel to toxicology studies. Given the current state of knowledge, it is appropriate for health impact assessment studies to assume that all particles, regardless of their source, have the same potential to cause disease.

Emissions of PM from biomass burning are rising globally, and thus, it is timely to consider what the impacts of this are for human health. There are many sources of biomass burning that can influence ambient PM levels. In Thailand, the current permanent air quality monitoring is limited in some areas, and thus, it is difficult to quantify the true impact of air pollution from different sources across the country. Additional monitoring, combined with modelling and satellite observations, would improve our understanding of biomass burning in the region. In Thailand, and SE Asia as a whole, large populations are affected by biomass-derived haze events, and thus, it is noteworthy that few epidemiological and experimental (in vitro and in vivo) studies have been conducted in this region to identify what risks may be posed to health; further research is therefore needed.

Acknowledgements The authors would like to thank Prof Vicki Stone (Heriot-Watt University) for her valuable feedback on the manuscript.

Funding Information This review was prepared as part of the TAPHIA (Thailand Air Pollution and Health Impact Assessment) project which is jointly funded by the Thai Research Fund (TRF) and the UK Medical Research Council (MRC) through the Newton Fund (Grant number MR/ R006210/1)

\section{Compliance with Ethical Standards}

Conflict of Interest On behalf of all authors, the corresponding author states that there is no conflict of interest.

Human and Animal Rights and Informed Consent This article does not contain any studies with human or animal subjects performed by any of the authors.

Open Access This article is distributed under the terms of the Creative Commons Attribution 4.0 International License (http:// creativecommons.org/licenses/by/4.0/), which permits unrestricted use, distribution, and reproduction in any medium, provided you give appropriate credit to the original author(s) and the source, provide a link to the Creative Commons license, and indicate if changes were made.

\section{References}

1. Dockery DW, Pope CA, Xu X, Spengler JD, Ware JH, Fay ME, et al. An association between air pollution and mortality in six US cities. N Engl J Med. 1993;329:1753-9.

2. Delfino RJ, Becklake MR, Hanley JA, Singh B. Estimation of unmeasured particulate air pollution data for an epidemiological study of daily respiratory morbidity. Environ Res. 1994;67:20-38.

3. Laden F, Schwartz J, Speizer FE, Dockery DW. Reduction in fine particulate air pollution and mortality: extended follow-up of the 
Harvard Six Cities study. Am J Respir Crit Care Med. 2006;173: 667-72.

4. Atkinson RW, Anderson HR, Sunyer J, Ayres J, Baccini M, Vonk $\mathrm{JM}$, et al. Acute effects of particulate air pollution on respiratory admissions results from APHEA 2 project. Am J Respir Crit Care Med. 2001;164:1860-6.

5. von Klot S, Wölke G, Tuch T, Heinrich J, Dockery DW, Schwartz $\mathrm{J}$, et al. Increased asthma medication use in association with ambient fine and ultrafine particles. Eur Respir J. 2002;20:691-702.

6. Pope CA III, Burnett RT, Thun MJ, Calle EE, Krewski D, Ito K, et al. Lung cancer, cardiopulmonary mortality, and long-term exposure to fine particulate air pollution. JAMA. 2002;287:113241.

7. Pope CA, Thun MJ, Namboodiri MM, Dockery DW, Evans JS, Speizer FE, et al. Particulate air pollution as a predictor of mortality in a prospective study of US adults. Am J Respir Crit Care Med. 1995;151:669-74.

8. American Thoracic Society (ATS). American Thoracic Society. What constitutes an adverse health effect of air pollution? Am J Respir Crit Care Med. 2000;161:665-73.

9. Brook RD, Franklin B, Cascio W, Hong Y, Howard G, Lipsett M, et al. Expert Panel on Population and Prevention Science of the American Heart Association. Air pollution and cardiovascular disease: a statement for healthcare professionals from the Expert Panel on Population and Prevention Science of the American Heart Association. Circulation. 2004;6083:2655-71.

10. WHO. Air quality guidelines - a global update. 2005.

11. Naeher LP, et al. Woodsmoke health effects: a review. Inhal Toxicol. 2007;19(1):67-106.

12. Kelly FJ, Fussell JC. Size, source and chemical composition as determinants of toxicity attributable to ambient particulate matter. Atmos Environ. 2012;60:504-26.

13. Wu W, Jin Y, Carlsten C. Inflammatory health effects of indoor and outdoor particulate matter. J Allergy Clin Immunol. 2019;141: 833-44.

14. Hoek G, Krishnan RM, Beelen R, Peters A, Ostro B, Brunekreef $\mathrm{B}$, et al. Long-term air pollution exposure and cardio-respiratory mortality: a review. Environ Health. 2013;12:43.

15. Samet J, Krewski D. Health effects associated with exposure to ambient air pollution. J Toxic Environ Health A Curr Issues. 2007;70:227-42.

16. Rantf U, Schikowski T, Sugiri D, Krutmann J, Krämer U. Longterm exposure to traffic-related particulate matter impairs cognitive function in the elderly. Environ Res. 2009;109:1004-11.

17. Pearson JF, Bachireddy C, Shyamprasad S, Goldfine AB, Brownstein JS. Association between fine particulate matter and diabetes prevalence in the U.S. Diabetes Care. 2010;33:2196201.

18. Wu Y, Lin YC, Yu HL, Chen JH, Chen TF, Sun Y, et al. Association between air pollutants and dementia risk in the elderly. Alzheimers Dement. 2015;1:220-8.

19. Heusinkveld HJ, Wahle T, Campbell A, Westerink RHS, Tran L, Johnston $\mathrm{H}$, et al. Neurodegenerative and neurological disorders by small inhaled particles. Neurotoxicology. 2016;56:94-106.

20. Alderete TL, et al. Ambient and traffic-related air pollution exposures as novel risk factors for metabolic dysfunction and type 2 diabetes. Curr Epidemiol Rep. 2018;5(2):79-91.

21. Dimakakou E, Johnston HJ, Streftaris G, Cherrie J. Exposure to environmental and occupational particulate air pollution as a potential contributor to neurodegeneration and diabetes: a systematic review of epidemiological research. Int J Environ Res Public Health. 2018;15:E1704.

22. Yang BY, Qian ZM, Li S, Chen G, Bloom MS, Elliott M, et al. Ambient air pollution in relation to diabetes and glucosehomoeostasis markers in China: a cross-sectional study with findings from the 33 Communities Chinese Health Study. Lancet Planet Health. 2018;2:e64-73.

23. Radojevic M, Hassan H. Air quality in Brunei Darussalam during the 1998 haze episode. Atmos Environ. 1999;33:3651-8.

24. Lohman DJ, Bickford D, Sodhi NS. Environment: the burning issue. Science. 2007;316:376.

25. Li X, Jin L, Kan H. Air pollution: a global problem needs local fixes. Nature. 2019;570:437-9.

26. Hime N, Marks G, Cowie C. A comparison of the health effects of ambient particulate matter air pollution from five emission sources. Int J Environ Res Public Health. 2018;15:1206.

27. Delfino RJ, Staimer N, Gillen D, Tjoa T, Sioutas C, Fung K, et al. Personal and ambient air pollution is associated with increased exhaled nitric oxide in children with asthma. Environ Health Perspect. 2006;114:1736-43.

28. Kodavanti UP, Schladweiler MC, Ledbetter AD, McGee JK, Walsh L, Gilmour PS, et al. Consistent pulmonary and systemic responses from inhalation of fine concentrated ambient particles: roles of rat strains used and physicochemical properties. Environ Health Perspect. 2005;113:1561-8.

29. Grahame TJ, Schlesinger RB. Health effects of airborne particulate matter: do we know enough to consider regulating specific particle types or sources? Inhal Toxicol. 2008;19:457-81.

30. Janssen NA, Hoek G, Simic-Lawson M, Fischer P, van Bree L, ten Brink $\mathrm{H}$, et al. Black carbon as an additional indicator of the adverse health effects of airborne particles compared with PM10 and PM2.5. Environ Health Perspect. 2011;119:1691-9.

31. Steenhof M, Gosens I, Strak M, Godri KJ, Hoek G, Cassee FR, et al. In vitro toxicity of particulate matter (PM) collected at different sites in the Netherlands is associated with PM composition, size fraction and oxidative potential - the RAPTES project. Part Fibre Toxicol. 2011;8:26.

32. Dergham M, Lepers C, Verdin A, Cazier F, Billet S, Courcot D, et al. Temporal-spatial variations of the physicochemical characteristics of air pollution particulate matter (PM2.5-0.3) and toxicological effects in human bronchial epithelial cells (BEAS-2B). Environ Res. 2015;137:256-67.

33. Seaton A, MacNee W, Donaldson K, Godden D. Particulate air pollution and acute health effects. Lancet. 1995;345:176-8.

34. Donaldson K, Stone V. Current hypotheses on the mechanisms of toxicity of ultrafine particles. Ann Ist Super Sanita. 2003;39:40510.

35. Oberdörster G, Stone V, Donaldson K. Toxicology of nanoparticles: a historical perspective. Nanotoxicology. 2007;1:2-25.

36. Stone V, Miller MR, Clift MJD, Elder A, Mills NL, Møller P, et al. Nanomaterials versus ambient ultrafine particles: an opportunity to exchange toxicology knowledge. Environ Health Perspect. 2017;125(1-17).

37. Li N, Xia T, Nel AE. The role of oxidative stress in ambient particulate matter-induced lung diseases and its implications in the toxicity of engineered nanoparticles. Free Radic Biol Med. 2008;44:1689-99.

38. Godleski JJ, Verrier RL, Koutrakis P, Catalano P, Coull B, Reinisch $U$, et al. Mechanisms of morbidity and mortality from exposure to ambient air particles. Res Rep Health Eff Inst. 2000;91:5-88

39. Krzyzanowski M, Kuna-Dibbert B, Schneider J. WHO Report: health effects of transport-related air pollution. 2005.

40. Guofeng S, Siye W, Wen W, Yanyan Z, Yujia M, Bin W, et al. Emission factors, size distributions, and emission inventories of carbonaceous particulate matter from residential wood combustion in rural China. Environ Sci Technol. 2012;46.

41. Sigsgaard T, Forsberg B, Annesi-Maesano I, Blomberg A, Bølling A, Boman C, et al. Health impacts of anthropogenic biomass burning in the developed world. Eur Respir J. 2015;46:1577-88. 
42. Defra. The potential air quality impacts from biomass combustion. 2017.

43. He C, Miljevic B, Crilley LR, Surawski NC, Bartsch J, Salimi F, et al. Characterisation of the impact of open biomass burning on urban air quality in Brisbane, Australia. Environ Int. 2016;91: $230-42$.

44. Zelikoff JT, Chen LC, Cohen MD, Schlesinger RB. The toxicology of inhaled woodsmoke. J Toxicol Environ Health Part B Crit Rev. 2002;5:269-82.

45. Glasius M, Ketzel M, Wahlin P, Jensen B, Monster J, Berkowicz $\mathrm{R}$, et al. Impact of wood combustion on particle levels in a residential area in Denmark. Atmos Environ. 2006;40:7115-24.

46. Fuller GW, Tremper AH, Baker TD, Espen K, Butter D. Contribution of wood burning to PM10 in London. Atmos Environ. 2014;87:87-94.

47. Snider G, Carter E, Clark S, Tseng JTW, Yang X, Ezzati M, et al. Impacts of stove use patterns and outdoor air quality on household air pollution and cardiovascular mortality in southwestern China. Environ Int. 2018;117:116-24.

48. Wu X, Vu TV, Shi Z, Harrison RM, Liu D, Cen K. Characterization and source apportionment of carbonaceous PM 2.5 particles in China - a review. Atmos Environ. 2018;189:187212.

49. Kim YH, Warren SH, Krantz QT, King C, Jaskot R, Preston WT, et al. Mutagenicity and lung toxicity of smoldering vs. flaming emissions from various biomass fuels: implications for health effects from wildland fires. Environ Health Prev Med. 2018;126(017011):1-14.

50. Sapkota A, Symons JM, Kleissl J, Wang L, Parlange MB, Ondov J, et al. Impact of the 2002 Canadian forest fires on particulate matter air quality in Baltimore City. Environ Sci Technol. 2005;39:24-32.

51. Artaxo P, Yamasoe MA. Fine mode aerosol composition at three long-term atmospheric monitoring sites in the Amazon Basin. J Geophys Res-Atmos. 1994;99:22857. https://doi.org/10.1029/ 94JD01023.

52. Wegesser TC, Pinkerton KE, Last JA. California wildfires of 2008: coarse and fine particulate matter toxicity. Environ Health Perspect. 2009;117:893-7.

53. Phuleria HC, Fine PM, Zhu Y. Air quality impacts of the October 2003 Southern California wildfires. J Geophys Res-Atmos. 2005;110(1-11).

54. Cheewaphongphan P, Junpen A, Garivait S, Chatani S. Emission inventory of on-road transport in Bangkok metropolitan region (BMR) development during 2007 to 2015 using the GAINS model. Atmosphere (Basel). 2017;8:167.

55. Pham TBT, Manomaiphiboon K, Vongmahadlek C. Development of an inventory and temporal allocation profiles of emissions from power plants and industrial facilities in Thailand. Sci Total Environ. 2008;397:103-18.

56. Vongmahadlek C, Bich Thao PT, Satayopas B, Thongboonchoo N. A compilation and development of spatial and temporal profiles of high-resolution emissions inventory over Thailand. J Air Waste Manage Assoc. 2009;59:845-56.

57. Sornpoon W, Bonnet S, Kasemsap P, Prasertsak P, Garivait S. Estimation of emissions from sugarcane field burning in Thailand using bottom-up country-specific activity data. Atmosphere. 2014;5(3):669-85. https://doi.org/10.3390/ atmos5030669.

58. Phairuang W, Hata M, Furuuchi M. Influence of agricultural activities, forest fires and agro-industries on air quality in Thailand. J Environ Sci. 2016;52:85-97.

59. Brauer M, Hisham-Hashim J. Fires in Indonesia: crisis and reaction. Environ Sci Technol. 1998:32:404A-7A.
60. Outapa P, Ivanovitch K. Effect of seasonal variation and Meterological data on PM10 concentrations in northern Thailand. Int J Geomate. 2019;16:46-53.

61. Tsai YI, Sopajaree K, Chotruksa A, Wu HC, Kuo SC. Source indicators of biomass burning associated with inorganic salts and carboxylates in dry season ambient aerosol in Chiang Mai Basin, Thailand. Atmos Environ. 2013;78:93-104.

62. Moran J, NaSuwan C, Poocharoen O-O. The haze problem in northern Thailand and policies to combat it: a review. Environ Sci Pol. 2019;97:1-15.

63. Lee JSH, Jaafar Z, Tan AKJ, Carrasco LR, Ewing JJ, Bickford DP, et al. Toward clearer skies: challenges in regulating transboundary haze in Southeast Asia. Environ Sci Pol. 2016;55(87):95.

64. Phairuang W, Suwattiga P, Chetiyanukornkul T, Hongtieab S, Limpaseni W, Ikemori F, et al. The influence of the open burning of agricultural biomass and forest fires in Thailand on the carbonaceous components in size-fractionated particles. Environ Pollut. 2019;247:238-47.

65. Kliengchuay W, Meeyai AC, Worakhunpiset S, Tantrakarnapa K. Relationships between meteorological parameters and particulate matter in Mae Hong Son province, Thailand. Int J Environ Res Public Health. 2018;15.

66. Johnston HJ, Verdon R, Gillies S, Brown DM, Fernandes TF, Henry TB, et al. Adoption of in vitro systems and zebrafish embryos as alternative models for reducing rodent use in assessments of immunological and oxidative stress responses to nanomaterials. Crit Rev Toxicol. 2018;48:252-71.

67. Chen J, Li C, Ristovski Z, Milic A, Gu Y, Islam MS, et al. A review of biomass burning: emissions and impacts on air quality, health and climate in China. Sci Total Environ. 2017;579:100034.

68. Mangia C, Cervino M, Gianicolo EAL. Secondary particulate matter originating from an industrial source and its impact on population health. Int J Environ Res Public Health. 2015;12: 7667-81.

69. Tan WC, Qiu D, Liam BL, Ng TP, Lee SH, van Eeden SF, et al. The human bone marrow response to acute air pollution caused by Forest fires. Am J Respir Crit Care Med. 2000;161:1213-7.

70. Swiston JR, Davidson W, Attridge S, Li GT, Brauer M, van Eeden SF. Wood smoke exposure induces a pulmonary and systemic inflammatory response in firefighters. Eur Respir J. 2008;32: 129-38.

71. Jayachandran S. Air quality and early-life mortality evidence from Indonesia's wildfires. J Hum Resour. 2009;44:916-54.

72. Morgan G, Sheppeard V, Khalaj B, Ayyar A, Lincoln D, Jalaludin B, et al. Effects of bushfire smoke on daily mortality and hospital admissions in Sydney, Australia. Epidemiology. 2010;21:47.

73. Rappold AG, Stone SL, Cascio WE, Neas LM, Kilaru VJ, Carraway MS, et al. Peat bog wildfire smoke exposure in rural North Carolina is associated with cardiopulmonary emergency department visits assessed through syndromic surveillance. Environ Health Perspect. 2011;119:1415-20.

74. Holstius DM, Reid CE, Jesdale BM, Morello-Frosch R. Birth weight following pregnancy during the 2003 southern California wildfires. Environ Health Perspect. 2012;120:1340-5.

75. da Silva C, Moi GP, Mattos IE, Hacon SDS. Low birth weight at term and the presence of fine particulate matter and carbon monoxide in the Brazilian Amazon: a population-based retrospective cohort study. BMC Pregnancy and Childbirth. 2014;14(309).

76. Dennekamp M, Straney LD, Erbas B, Abramson MJ, Keywood $\mathrm{M}$, Smith K, et al. Forest fire smoke exposures and out-of-hospital cardiac arrests in Melbourne, Australia: a case-crossover study. Environ Health Perspect. 2015;123:959-64.

77. Haikerwal A, Akram M, Del Monaco A, Smith K, Sim MR, Meyer M, et al. Impact of fine particulate matter (PM 2.5) 
exposure during wildfires on cardiovascular health outcomes. J Am Heart Assoc. 2015;4:1-10.

78. Kim K, Jahan SA, Kabir E. A review of diseases associated with household air pollution due to the use of biomass fuels. J Hazard Mater. 2011;192:425-31.

79. Liu JC, Pereira G, Uhl SA, Bravo MA, Bell ML. A systematic review of the physical health impacts from non-occupational exposure to wildfire smoke. Environ Res. 2015;136:120-32.

80. Black C, Tesfaigzi Y, Bassein JA, Miller LA. Wildfire smoke exposure and human health: significant gaps in research for a growing public health issue. Environ Toxicol Pharmacol. 2017;55:186-95.

81. Williamson GJ, Bowman DMJS, Price OF, Henderson SB, Johnston FH. A transdisciplinary approach to understanding the health effects of wildfire and prescribed fire smoke regimes. Environ Res Lett. 2016;11:125009.

82. Reid CE, Brauer M, Johnston FH, Jerrett M, Balmes JR, Elliott C. Critical review of health impacts of wildfire smoke exposure. Environ Health Perspect. 2016;124:1334-43.

83. Gehring U, Tamburic L, Sbihi H, Davies HW, Brauer M. Impact of noise and air pollution on pregnancy outcomes. Epidemiology. 2014;25:351-8.

84. Lakshmi PV, Virdi NK, Sharma A, Tripathy JP, Smith KR, Bates $\mathrm{MN}$, et al. Household air pollution and stillbirths in India: analysis of the DLHS-II National Survey. Environ Res. 2013;121:17-22.

85. Smith KR, Samet JM, Romieu I, Bruce N. Indoor air pollution in developing countries and acute lower respiratory infections in children. Thorax. 2000;55(6):518-32.

86. Perez-Padilla R, Schilmann A, Riojas-Rodriguez H. Respiratory health effects of indoor air pollution. Int $\mathrm{J}$ Tuberc Lung Dis. 2010;14:1079-86.

87. Dubick MA, Carden SC, Jordan BS, Langlinais PC, Mozingo DW. Indices of antioxidant status in rats subjected to wood smoke inhalation and/or thermal injury. Toxicology. 2002;176:145-57.

88. Seagrave J, McDonald JD, Bedrick E, Edgerton ES, Gigliotti AP, Jansen JJ, et al. Lung toxicity of ambient particulate matter from southeastern U.S. sites with different contributing sources: relationships between composition and effects. Environ Health Perspect. 2006;114:1387-93.

89. Wegesser TC, Franzi LM, Mitloehner FM, Eiguren-Fernandez A, Last J. Lung antioxidant and cytokine responses to coarse and fine particulate matter from the great California wildfires of 2008 . Inhal Toxicol. 2010;22:561-70.

90. Danielsen PH, Møller P, Jensen KA, Sharma AK, Wallin H, Bossi $\mathrm{R}$, et al. Oxidative stress, DNA damage, and inflammation induced by ambient air and wood smoke particulate matter in human A549 and Thp-1 cell lines. Chem Res Toxicol. 2011;24:168-84.

91. Happo MS, Salonen RO, Hälinen AI, Jalava PI, Pennanen AS. Inflammation and tissue damage in mouse lung by single and repeated dosing of urban air coarse and fine particles collected from six European cities. Inhal Toxicol. 2010;22(5):402-16.

92. Kim YH, Tong H, Daniels M, Boykin E, Krantz QT, McGee J, et al. Cardiopulmonary toxicity of peat wildfire particulate matter and the predictive utility of precision cut lung slices. Part Fibre Toxicol. 2014;11:29.

93. Mirowsky J, Hickey C, Horton L, Blaustein M, Galdanes K, Peltier RE, et al. The effect of particle size, location and season on the toxicity of urban and rural particulate matter. Inhal Toxicol. 2013;25:747-57.

94. Sussan TE, Ingole V, Kim JH, McCormick S, Negherbon J, Fallica $\mathrm{J}$, et al. Source of biomass cooking fuel determines pulmonary response to household air pollution. Am J Respir Crit Care Med. 2014;50:538-48.

95. Plummer LE, Carosino CM, Bein KJ, Zhao Y, Willits N, SmileyJewell S, et al. Pulmonary inflammatory effects of source-oriented particulate matter from California's San Joaquin Valley. Atmos Environ. 1994;119:174-81.

96. Kim YH, King C, Krantz T, Hargrove MM, George IJ, McGee J, et al. The role of fuel type and combustion phase on the toxicity of biomass smoke following inhalation exposure in mice. Arch Toxicol. 2019;93(6):1501-13.

97. Kelly FJ. Oxidative stress: its role in air pollution and adverse health effects. Occup Environ Med. 2003;60:612-6.

98. Leonard SS, Wang S, Shi X, Jordan BS, Castranova V, Dubick MA. Wood smoke particles generate free radicals and cause lipid peroxidation, DNA damage, NFKB activation and TNF- $\alpha$ release in macrophages. Toxicology. 2000;150:147-57.

99. Jalava PI, Salonen RO, Hälinen AI, Penttinen P, Pennanen AS, Sillanpää $\mathrm{M}$, et al. In vitro inflammatory and cytotoxic effects of size-segregated particulate samples collected during long-range transport of wildfire smoke to Helsinki. Toxicol Appl Pharmacol. 2006;215:341-53.

100. Karlsson HL, Ljungman AG, Lindbom J, Lennart M. Comparison of genotoxic and inflammatory effects of particles generated by wood combustion, a road simulator and collected from street and subway. Toxicol Lett. 2006;165:203-11.

101. Leonard SS, Castranova V, Chen BT, Schwegler-Berry D, Hoover $\mathrm{M}$, Piacitelli $\mathrm{C}$, et al. Particle size-dependent radical generation from wildland fire smoke. Toxicology. 2007;236:103-13.

102. Karlsson HL, Holgersson Å, Möller L. Mechanisms related to the genotoxicity of particles in the subway and from other sources. Chem Res Toxicol. 2008;21:726-31.

103. Guastadisegni C, Kelly FJ, Cassee FR, Gerlofs-nijland ME, Janssen NAH. Determinants of the proinflammatory action of ambient particulate matter in immortalized murine macrophages. Environ Health Perspect. 2010;118:1728-34. https://doi.org/10. 1289/ehp.1002105.

104. Franzi LM, Bratt JM, Williams KM, Last JA. Why is particulate matter produced by wild fires toxic to lung macrophages? Toxicol Appl Pharmacol. 2011;257:182-8.

105. Wong LSN, Aung HH, Lamé MW, Wegesser TC, Wilson DW. Fine particulate matter from urban ambient and wildfire sources from California's San Joaquin Valley initiate differential inflammatory, oxidative stress, and xenobiotic responses in human bronchial epithelial cells. Toxicol Vitro. 2011;25:1895-905.

106. Tapanainen M, Jalava PI, Mäki-Paakkanen J, Hakulinen P, Lamberg H, Ruusunen J, et al. Efficiency of log wood combustion affects the toxicological and chemical properties of emission particles. Inhal Toxicol. 2012;24:343-55.

107. Corsini E, Budello S, Marabini L, Galbiati V, Piazzalunga A, Barbieri P, et al. Comparison of wood smoke PM2.5 obtained from the combustion of FIR and beech pellets on inflammation and DNA damage in A549 and THP-1 human cell lines. Arch. Toxicol. 2013;87:2187-99.

108. Perrone MG, Gualtieri M, Consonni V, Ferrero L, Sangiorgi G, Longhin E, et al. Particle size, chemical composition, seasons of the year and urban, rural or remote site origins as determinants of biological effects of particulate matter on pulmonary cells. Environ Pollut. 2013;176:215-27.

109. Miousse IR, Chalbot MC, Pathak R, Lu X, Nzabarushimana E, Krager K, et al. In vitro toxicity and epigenotoxicity of different types of ambient particulate matter. Toxicol Sci. 2015;148:47387.

110. Longhin E, Gualtieri M, Capasso L, Bengalli R, Mollerup S, Holme JA, et al. Physico-chemical properties and biological effects of diesel and biomass particles. Environ Pollut. 2016;215: 366-75.

111. Jin W, Su S, Wang B, Zhu X, Chen Y, Shen G, et al. Properties and cellular effects of particulate matter from direct emissions and ambient sources. J Environ Sci Health Part A. 2016;51:1075-83. 
112. Park M, Joo HS, Lee K, Jang M, Kim SD, Kim I, et al. Differential toxicities of fine particulate matters from various sources. Sci Rep. 2018;8:17007.

113. Van Den Heuvel R, Staelens J, Koppen G, Schoeters G. Toxicity of urban PM10 and relation with tracers of biomass burning. Int J Env. Res Public Health. 2018;15:E320.

114. Marchetti S, Longhin E, Bengalli R, Avino P, Stabile L, Buonanno $\mathrm{G}$, et al. In vitro lung toxicity of indoor PM10 from a stove fueled with different biomasses. Sci Total Environ. 2019;649:1422-33.

115. Lehmann AD, Daum N, Bur M, Lehr CM, Gehr P, RothenRutishauser BM. An in vitro triple cell co-culture model with primary cells mimicking the human alveolar epithelial barrier. Eur J Pharm Biopharm. 2011;77:398-406.

116. Liu Q, Baumgartner J, Zhang Y, Liu Y, Sun Y, Zhang M. Oxidative potential and inflammatory impacts of source apportioned ambient air pollution in Beijing. Environ Sci Technol. 2014;48:12920-9.

117. Brown DM, Stone V, Findlay P, MacNee W, Donaldson K. Increased inflammation and intracellular calcium caused by ultrafine carbon black is independent of transition metals or other soluble components. Occup Environ Med. 2000;57:685-91.
118. Teeguarden JG, Mikheev VB, Minard KR, Forsythe WC, Wang W, Sharma G, et al. Comparative iron oxide nanoparticle cellular dosimetry and response in mice by the inhalation and liquid cell culture exposure routes. Part Fibre Toxicol. 2014;11(46).

119. Duffin R, Tran L, Brown D, Stone V, Donaldson K. Proinflammogenic effects of low-toxicity and metal nanoparticles in vivo and in vitro: highlighting the role of particle surface area and surface reactivity. Inhal Toxicol. 2007;19:849-56.

120. Kiatwattanacharoen S, Prapamontol T, Singharat S, Chantara S, Thavornyutikarn P. Exploring the sources of PM10 burningseason haze in northern Thailand using nuclear analytical techniques, Chiang Mai Univ. J Nat Sci. 2017;16:307.

Publisher's Note Springer Nature remains neutral with regard to jurisdictional claims in published maps and institutional affiliations. 